\title{
Synaptic Plasticity in the Basolateral Amygdala Induced by Hippocampal Formation Stimulation in vivo
}

\author{
Stephen Maren and Michael S. Fanselow \\ Department of Psychology, University of California, Los Angeles, California 90024-1563
}

\begin{abstract}
Several studies suggest that axonal projections from the hippocampal formation (HF) to the basolateral amygdala (BLA) play a role in Pavlovian fear conditioning to contextual conditional stimuli. We have used electrophysiological techniques to characterize neuronal transmission in these projections in urethane-anesthetized rats. Single-pulse electrical stimulation of the ventral angular bundle (VAB), which carries projections from the HF to the BLA, reliably evoked a biphasic extracellular field potential in the BLA that consisted of an early, negative and a late, positive component. The negative component of the field potential occurred at a short latency (3-8 $\mathrm{msec})$, was both temporally and spatially correlated with VAB-evoked multiple-unit discharges in the BLA, and exhibited properties typical of a monosynaptic response. Infusion of lidocaine or glutamate receptor antagonists into the BLA attenuated VABevoked field potentials, indicating that they are generated by local synaptic glutamatergic transmission. Both pairedpulse stimulation and brief trains of high-frequency stimulation (HFS) induced a short-lasting facilitation of BLA field potentials, whereas longer and more numerous trains of HFS produced an enduring, NMDA receptor-dependent long-term potentiation (LTP) of the potentials. The induction of LTP was accompanied by a decrease in paired-pulse facilitation (PPF), suggesting a presynaptic modification underlying its expression. Electrolytic lesions placed in regions of the HF that project to the BLA or excitotoxic lesions placed in the BLA eliminated Pavlovian fear conditioning to a contextual conditional stimulus. The critical role of both structures in context conditioning implicates plasticlty at HF-BLA synapses in this form of learning.

[Key words: amygdala, hippocampus, long-term potentiation, paired-pulse facilitation, glutamate, Pavlovian fear conditioning, anesthetized rat]
\end{abstract}

Convergent lines of evidence indicate that the basolateral amygdala (BLA) is a critical component of a neural circuit underlying Pavlovian fear conditioning in mammals (see Davis et al., 1994, for a recent review). Although many neurotransmitter systems in the BLA have been implicated in fear conditioning, recent attention has been directed toward the role of glutamatergic syn-

\footnotetext{
Received Mar. 15, 1995; revised July 14, 1995; accepted July 19, 1995.

This work was supported by a grant from the NIMH (MH39786) to M.S.F. S.M. was supported by an institutional NIMH National Research Service Award (MH15795).

Correspondence should be addressed to Stephen Maren, Department of Psychology. University of California, 405 Hilgard Avenue, Los Angeles, CA 90024-1563.

Copyright (1) 1995 Society for Neuroscience 0270-6474/95/157548-17\$05.00/0
}

aptic transmission in this form of learning. Several laboratories have now demonstrated that intra-amygdaloid infusion of the NMDA receptor antagonist, D,L-2-amino-5-phosphonovalerate (APV), prevents learning in tasks that require the amygdala (Miserendino et al., 1990; Jerusalinsky et al., 1992; Fanselow and Kim, 1994; Liang et al., 1994). Furthermore, blockade of non-NMDA glutamate receptors ( $\alpha$-amino-3-hydroxy-5-methyl4-isoxazolepropionate or AMPA receptors) in the BLA prevents the expression of learned fear (Izquierdo et al., 1993; Kim et al., 1993). Collectively, these studies indicate an important role for glutamate receptors in both the acquisition and performance of conditional fear.

The involvement of glutamate receptors in fear conditioning has led to the suggestion that this form of learning is mediated by long-term potentiation (LTP) of synaptic transmission in the BLA. As the prototypical form of long-term synaptic plasticity in the brain, LTP is an enduring enhancement of synaptic efficacy that has been suggested to play a role in learning and memory processes (see Maren and Baudry, 1995, for a recent review). It is induced experimentally by applying brief trains of high-frequency electrical stimulation to excitatory synapses (e.g., Bliss and Gardner-Medwin, 1973; Bliss and Lømo, 1973) and, as suggested above, requires glutamate receptors for both induction and expression. In the hippocampus, for example, LTP induction requires NMDA receptor activation (Collingridge et al., 1983; Morris et al., 1986; Maren et al., 1992) and expression is mediated, in part, by a change in the properties of postsynaptic AMPA receptors (Muller et al., 1988; Xiao et al., 1991; Shahi and Baudry, 1992; Maren et al., 1993).

Although fear conditioning has been suggested to be mediated by LTP in the BLA, relatively little is known about the nature of BLA LTP. To date, only two reports have investigated LTP in the BLA in vivo (Racine et al., 1983; Clugnet and LeDoux, 1990), and these investigations have been limited. Relatively more work has been done on the synaptic mechanisms of BLA LTP using in vitro preparations (e.g., Chapman et al. 1990; Chapman and Bellevance, 1991; Gean et al., 1993), although these preparations are not amenable to behavioral studies of BLA LTP. As a first step in developing a BLA LTP preparation that can be easily adapted to behavioral studies, we have undertaken an electrophysiological analysis of synaptic transmission and synaptic plasticity in projections from the hippocampal formation (HF) to the BLA in urethane-anesthetized rats.

There are several reasons for choosing to analyze HF-BLA synaptic transmission. First, anatomical studies have revealed that a prominent source of BLA afferents is the HF. These projections course through the ventral angular bundle (VAB) and arise from hippocampal area $\mathrm{CA}_{1}$, the ventral subiculum, and 
the lateral entorhinal cortex (Ottersen, 1982; Canteras and Swanson, 1992). Second, intracellular recording studies have suggested that HF-BLA projections are monosynaptic (Mello et al., 1992a) and glutamatergic (Mello et al., 1992b). Finally, the HFBLA projection is suspected of having a specific role in Pavlovian fear conditioning, that of conveying information about contextual stimuli from the HF to the BLA. The goals of the present study were to characterize synaptic transmission and synaptic plasticity at HF-BLA synapses and to examine the contribution of the $\mathrm{HF}$ and BLA to Pavlovian fear conditioning.

\section{Materials and Methods}

Subjects. The subjects were 115 adult male Long-Evans rats (300-550 $\mathrm{gm}$ ) born and raised in the Department of Psychology vivarium at the University of California, Los Angeles. Seventy-nine rats were used in electrophysiological experiments and 36 rats were used in behavioral studies. Prior to surgery, the rats were individually housed for at least $5 \mathrm{~d}$ and handled daily. They were maintained on a 14:10 light: dark cycle and allowed free access to food and water. All electrophysiological and behavioral testing was performed during the light phase of the cycle.

Surgical procedures. In preparation for electrophysiological recording, the rats were ancsthctized with an intraperitoneal injection of ure thane (1.6 gm/ $\mathrm{kg}$ body weight) and mounted in a stereotaxic apparatus (David Kopf Instruments, Tujunga, CA). The scalp was incised and retracted, and head position was adjusted to place bregma and lambda in the same horizontal plane. Small burr holes $(2 \mathrm{~mm}$ diameter $)$ were drilled unilaterally in the skull for the placement of stimulating and recording electrodes (described below). Using stereotaxic criteria and the auditory signals generated from multiple-unit discharges, the recording electrode was implanted in the BLA $(3.3 \mathrm{~mm}$ posterior to breg$\mathrm{ma}, 5.0 \mathrm{~mm}$ lateral to the midsagittal suture, and $6-8 \mathrm{~mm}$ ventral to the dural surface). After placement of the recording electrode, the stimulating electrode was implanted in the VAB $(6.3 \mathrm{~mm}$ posterior to bregma, $5.0 \mathrm{~mm}$ lateral to the midsagittal suture, and $6-7 \mathrm{~mm}$ ventral to the dural surface). In most experiments, the ventral location of the recording and stimulating clectrodes was adjusted to maximize the amplitude of VAB-evoked field potentials in the BLA. During the course of the experiment, body temperature was maintained at $37^{\circ} \mathrm{C}$ with a feedbackregulated temperature controller (Cole-Parmer Instruments, Chicago, IL).

The electrodes consisted of Epoxylite-insulated stainless steel insect pins (size 00 ) with the recording and stimulating surfaces formed by removing the insulation at the tips; the electrode tip lengths were approximately 50 and $250 \mu \mathrm{M}$ for recording and stimulating electrodes, respectively. To reduce current spread from the site of stimulation, a bipolar stimulating electrode was used. It consisted of two adjacent insect pins with a tip separation of $500 \mu \mathrm{M}$. A reference electrode consisting of a small stainless steel screw was affixed to the skull in the area overlying the nasal sinus.

For the behavioral studies, rats were randomly assigned to one of three groups: sham surgery ( $\mathrm{SH}, n=12$ ), electrolytic lesion of the ventrocaudal HF [entorhinal cortex, ventral subiculum, and VAB (HF), $n=12]$, and NMDA lesion of the BLA (BL, $n=12$ ). The rats were treated as above except that they were anesthetized with sodium pentobarbital $(65 \mathrm{mg} / \mathrm{kg})$. For bilateral HF lesions, a stainless steel electrode identical to those described above (tip length $=500 \mu \mathrm{M}$ ) was lowered into the ventrocaudal HF at two locations $(6.8 \mathrm{~mm}$ posterior to bregma, $5.0 \mathrm{~mm}$ lateral to the midsagittal suture, and $7.0 \mathrm{~mm}$ ventral to brain surface; $8.0 \mathrm{~mm}$ posterior to bregma, $5.0 \mathrm{~mm}$ lateral to the midsagittal suture, and $5.0 \mathrm{~mm}$ ventral to brain surface). Direct anodal current (1.0 $\mathrm{mA}$ ) was passed through the electrode for $20 \mathrm{sec}$ at each locus. For NMDA lesions of the BLA, a 28 gauge cannula was lowered into the amygdala bilaterally $(3.0 \mathrm{~mm}$ posterior to bregma, $5.0 \mathrm{~mm}$ lateral to the midline). A $10 \mu \mathrm{l}$ Hamilton syringe was mounted in an infusion pump (Harvard Apparatus, South Natick, MA) and connected to the injection cannula with polyethylene tubing. NMDA $(20 \mu \mathrm{g} / \mu \mathrm{l}$ in 100 mM phosphate-buffered saline, $\mathrm{pH}=7.6$, Signa Chemical Co., St. Louis, MO) was infused $(0.1 \mu \mathrm{l}$ per $\mathrm{min})$ for $2 \mathrm{~min}$ at $8.0 \mathrm{~mm}$ ventral to brain surface and for $1 \mathrm{~min}$ at $7.5 \mathrm{~mm}$ ventral to brain surface for each penetration. Five minutes were allowed atter each infusion for diffusion of the drug. Rats in the sham group were treated identically to the other two groups except that no electrodes or cannulae were lowered in to the brain. Following surgery, the incision was closed with wound clips and the rats were allowed to recover on a heating pad before returning to their home cage.

Electrophysiological recordings. All electrophysiological recordings was performed under surgical anesthesia. Biphasic current pulses $(0.1$ msec per cycle, 0.2-2 mA; World Precision Instruments, Sarasota, FL) were applied to the $\mathrm{VAB}$ to evoke extracellular field potentials in the BLA. BLA field potentials were amplified $(1000 \times)$ and filtered $(1 \mathrm{~Hz}$ to $5 \mathrm{kH} z$; A-M Systems, Everett, WA), displayed on an oscilloscope, and digitized $(20 \mathrm{kHz}$ ) and written to disk (DataWave Corp., Longmont, $\mathrm{CO}$ ). For some subjects, VAB-evoked multiple-unit activity in the BLA was also recorded (amplification $=10,000 \times$, filters $=500 \mathrm{~Hz}$ to 5 $\mathrm{kHz}$ ). In all experiments, test pulses were delivered at $0.05 \mathrm{~Hz}$ ( 1 pulse every $20 \mathrm{sec}$ ).

Electrophysiological testing began at least $30 \mathrm{~min}$ following electrode implantation, a period of time that allowed stabilization of the VABevoked field potentials. The specific testing procedures varied according to the demands of a particular experiment. The first series of rats $(n=$ 7) was used to map VAB-evoked field potentials in the BLA. For these animals, the recording electrode was moved through the full extent of the BLA in 100-500 $\mu \mathrm{M}$ increments and VAB-evoked responses (both field potentials and multiple-unit clusters) were collected. Five responses were collected at each recording site and averaged.

A second series of rats $(n=12)$ was used to characterize basic properties of HF-BLA synaptic transmission. First, input-output curves were constructed to describe the relationship between BLA field potentials and stimulus intensity. The curves were generated by recording $\mathrm{VAB}$-evoked responses to a range of 10 stimulation intensities. Two ranges of stimulation intensity were used: $20-200 \mu \mathrm{A}$ or $200-2000 \mu \mathrm{A}$. BLA field potentials in a subset of these rats $(n=7)$ were also tested for their responsivity to paired-pulse stimulation $(10-100 \mathrm{msec}$ interstimulus intervals in $10 \mathrm{msec}$ steps) and short trains of high-frequency stimulation (HFS, 10 pulses delivered at 50, 100, and $400 \mathrm{~Hz}$ ). The stimulation intensity used for both of these procedures was adjusted to produce a half-maximal response. A third series of rats $(n=5)$ was used to examine paired-pulse plasticity at a fixed interstimulus interval across a range of stimulus intensities. In all cases, five responses were collected for each condition (i.e., intensity, ISI, or frequency) and avcraged.

A fourth series of rats $(n=10)$ was used to assess whether VABevoked field potentials were generated in the BLA or whether they were volume-conducted from another site in the brain. In five rats, a $4 \%$ lidocaine $\mathrm{HCl}$ solution was infused into the BLA during recording (see below for infusion procedures); the remaining five rats received the saline vehicle. For these experiments, a $10 \mathrm{~min}$ preinfusion baseline was collected and followed immediately by drug infusion. After drug infusion, responses were collected for $60 \mathrm{~min}$; responses were collected every $20 \mathrm{sec}$ during the entire recording session. It was expected that lidocaine would attenuate VAB-evoked field potentials if they were generated in the BLA. A fifth serics of rats $(n=18)$ was used to examine the contribution of glutamate receptors to BLA field potentials. For this experiment, 6,7-dinitro-quinoxaline-2,3-dione (10 $\mathrm{mm}$ DNQX, $n=6$ ), D,L-2-amino-5-phosphonovalerate ( $100 \mathrm{~mm}$ D,L-APV, $n=6)$, or vehicle $(0.9 \%$ saline, $n=3$ or $100 \%$ dimethyl sulfoxide, $n=3)$ was infused during recording. These doses of DNQX and APV were chosen because they correspond to those used in behavioral studies (Jerusalinsky et al., 1992; Fanselow and Kim, 1994). Responses were collected as indicated for the lidocaine experiment

A sixth series of rats $(n=18)$ was used to examine long-term synaptic plasticity of BLA field potentials. Pilot experiments determined effective parameters for the induction of LTP, which consisted of 10 brief bursts $(200 \mathrm{msec})$ of $100 \mathrm{~Hz}$ stimulation delivered at $\mathrm{I} \mathrm{Hz}$ (a total of 200 pulses). For each rat, a 10 min pre-HFS baseline was collected at a stimulation intensity that elicited a field potential with an approximately $400 \mu \mathrm{V}$ negative component (this generally corresponded to a half-maximal response). Immediately following collection of the baseline, experimental rats $(n=6)$ received four HFS trains separated by 5 min; control rats received either the same number of pulses at a lowfrequency (LFS-1 Hz, $n=6$ ) or received test pulses alone (LFS-0.05 $\mathrm{Hz}, n=6$ ). Responses were collected (1 every $20 \mathrm{sec}$ ) during the stimulation sessions and for $60 \mathrm{~min}$ following the last stimulation session. Three additional rats were used to assess the NMDA receptordependence of BLA LTP. Following a 10 min baseline, $100 \mathrm{~mm}$ APV was infused into the BLA as described below. Five minutes after APV 
infusion, one HFS train was delivered and responses collected for 30 $\min$.

The final series of rats ( $n=5$ ) was used to assess paired-pulse plasticity before and after the induction of LTP. Rather than using single test stimuli during the recording session, paired-pulses (20 msec ISI) were used. This permitted us to simultaneously examine paired-pulse facilitation (PPF) and LTP during the entire recording session. As before, a 10 min baseline was collected prior to the delivery of HFS at a stimulation intensity that produced a $400 \mu \mathrm{V}$ negative component. In this experiment, only a single HFS train was given, consisting of 10 $200 \mathrm{msec}$ bursts of $100 \mathrm{~Hz}$ stimulation delivered at $1 \mathrm{~Hz}$. Field potentials were recorded for $60 \mathrm{~min}$ following the delivery of HFS.

Drug infusion. In some experiments, pharmacological compounds were infused into the BLA during the recording session. This was accomplished with a recording electrode/guide cannula assembly through which a smaller injection cannula could be inserted for drug infusion. The assembly consisted of a recording electrode identical to those described above and a guide cannula fabricated from 28 gauge stainless steel tubing; the tip of the recording electrode extended $1 \mathrm{~mm}$ beyond the end of the guide cannula. The injection cannula was fabricated from 33 gauge tubing and was attached to a $10 \mu \mathrm{l}$ Hamilton syringe with a long length of polyethylene tubing. The syringe, in turn, was mounted in an infusion pump (Harvard Apparatus, South Natick, MA). Ten seconds prior to infusion, the injection cannula was gently lowered into the guide cannula and extended $1 \mathrm{~mm}$ beyond the tip of the guide cannula (i.e., adjacent to the tip of the recording electrode). All drug infusion was performed by pressure-injection at a rate of $0.1 \mu \mathrm{l} / \mathrm{min}$ for a duration of $2 \mathrm{~min}$, yielding a total infusion volume of $0.2 \mu \mathrm{l}$. Three compounds were infused: $4 \%$ lidocaine $\mathrm{HCl}, 10 \mathrm{mM}$ DNQX, and 100 mM APV. Both lidocaine $\mathrm{HCl}$ (Sigma Chemical Co., St. Louis, MO) and APV (Sigma Chemical Co., St. Louis, MO) were dissolved in $0.9 \%$ saline; DNQX (Research Biochemicals International, Natick, MA) was dissolved in $100 \%$ dimethyl sulfoxide (DMSO, Sigma Chemical Co., St. Louis, MO).

Behavioral apparatus and procedures. Four identical observation chambers $[28 \times 21 \times 22$ (width $\times$ height $\times$ depth) $\mathrm{cm}$; Lafayette Instrument Co., North Lafayette, IN] were used for both conditioning and contextual fear testing. The chambers were constructed from two aluminum sidewalls and a Plexiglas rear wall, ceiling, and hinged front door. The chambers were situated in chests located in a well-lit and isolated room. A videocamera placed in front of the observation chambers allowed each subjects' behavior to be observed and recorded by an experimenter in an adjacent room. The floor of each chamber consisted of 18 stainless steel rods ( $4 \mathrm{~mm}$ diameter) spaced $1.5 \mathrm{~cm}$ apart (center-to-center). The rods were wired to a shock generator and scrambler (Lafayette Instrument Co., North Lafayette, IN) for the delivery of footshock unconditional stimuli (USs). A speaker located on one wall of the chamber permitted the delivery of acoustic conditional stimuli (CSs). The chambers were cleaned with $5 \%$ ammonium hydroxide solution and stainless steel pans containing a thin film of the same solution were placed underneath the grid floors before rats were placed inside. Background noise ( $70 \mathrm{~dB}$, A-scale) was supplied by ventilation fans and shock scramblers.

An additional set of four observation chambers $(28 \mathrm{w} \times 2 \mathrm{lh} \times 22 \mathrm{~d}$ $\mathrm{cm}$; Lafayette Instrument Co., North Lafayette, IN) located in an adjacent room were used for testing conditional fear to the tone. The chambers were constructed from two aluminum sidewalls and a Plexiglas rear wall, ceiling, and hinged front door. The chambers were situated in chests located in a quiet, dimly lit, and isolated room. Ambient light in the room was provided by a single lamp equipped with a $15 \mathrm{~W}$ red light bulb. The floor of each chamber consisted of 17 vertically staggered stainless steel rods (4 mm diameter) spaced $1.5 \mathrm{~cm}$ apart (center to center) and the outside of the rear wall of the chambers was covered with white construction paper. In addition, a white, opaque Plexiglas tent was inserted into each chamber so that the apex of the tent contacted the roof of the chamber and the open base of the tent fit into the bottom corners of the chamber. A speaker located on one wall of the chamber permitted the delivery of acoustic conditional stimuli (CSs). Background noise ( $70 \mathrm{~dB}, \mathrm{~A}$-scale) was supplied by a white noise generator. The chambers were cleaned with $1 \%$ acetic acid solution and stainless steel pans containing a thin film of the same solution were placed underneath the grid floors before rats were placed inside. A videocamera placed in front of the observation chambers allowed each subjects' behavior to be observed and recorded by an experimenter in an adjacent room.
On the day of conditioning, the rats were placed in the conditioning chambers in squads of four rats; the chamber position was counterbalanced for each squad and group. The rats received three tone $(10 \mathrm{sec}$, $90 \mathrm{~dB}, 2 \mathrm{kHz}$ )-footshock (1 $\mathrm{sec}, 0.5 \mathrm{~mA}$ ) pairings (74 $\mathrm{sec}$ ITI) $3 \mathrm{~min}$ after being placed in the chambers. Sixty-four seconds following the final shock, the rats were returned to their home cages. Fear conditioning on the training day was assessed by measuring freezing during the $64 \mathrm{sec}$ period following each of the three footshocks. Briefly, an observer who was blind to the experimental conditions scored each rat for freezing (behavioral immobility except for movement necessitated by respiration) every $8 \mathrm{sec}$ for a total of eight observations per animal. Twenty-four hours following training, fear conditioning to the context was assessed by returning the rats to the conditioning chambers and scoring freezing during an 8 min test for a total of 64 observations per rat. On the following day, fear conditioning to the tone was assessed. The rats were placed in observation chambers that were distinct from those used during conditioning and, after 2 min, presented with an 8 min tone. Freezing to both the context and tone was scored as described for the immediate postshock freezing. All freezing scores were transformed to a percentage of total observations.

Histology. For the electrophysiological experiments, histological ver ification of recording and stimulating electrode locations was performed on a subset of the rats $(n=59)$. After electrophysiological testing. marking lesions were made by passing anodal current $(100 \mu \mathrm{A})$ for 5 sec. The rats were perfused across the heart with $0.9 \%$ saline followed by $10 \%$ formaldehyde solution. Coronal sections $(40 \mu \mathrm{M})$ were cut on a cryostat and mounted on glass microscope slides. Sections were stained with Prussian blue to reveal metal deposits at the recording and stimulating sites and thionin to visualize cell bodies. Electrode placements were verified by visual inspection of the sections. The tissue from rats with brain lesions ( $n=24$ ) was treated similarly, except that the Prussian blue staining was omitted.

Data analysis. All electrophysiological data were analyzed off-line using waveform analysis software (DataWave Corp., Longmont, CO). Three field potential parameters were chosen a priori for analysis: the slope and amplitude of the negative $\left(N_{1}\right)$ component and the amplitude of the positive $\left(P_{1}\right)$ component of the potential. Latency to spike firing and latency to the onset of the field potential components was also computed. All electrophysiological measures were analysed with analysis of variance. (ANOVA). Planned comparisons in the form of univariate $F$ tests or Fisher tests were performed following a significant omnibus $F$ ratio. Behavioral data consisted of probability estimates of freezing and were analyzed similarly. All data are represented as means \pm the standard errors of the means (SEMs).

\section{Results}

\section{Localization of stimulating and recording electrodes}

Histological examination of electrode placement was performed in 59 of the 79 subjects. As shown in Figure 1, recording electrode placements were concentrated in the posterior divisions of the basolateral, basomedial, and lateral nuclei of the amygdala. In general, the recording electrode tips were placed just ventral to the lateral ventricle, which served as a convenient landmark for electrode placement. Stimulating electrodes were placed in the region of the $\mathrm{VAB}$, often in the ventral subiculum and lateral entorhinal cortex. Because fibers arising from the temporal field of hippocampal area $\mathrm{CA}_{1}$, the ventral subiculum, and the lateral entorhinal cortex all course through the region where the stimulating electrode was placed, the projection field activated by VAB stimulation is not precisely defined. However, considering the relative sizes of these amygdala projection systems, the subiculo-amygdala projection (the largest of the three projections) is probably the substrate for VAB-evoked responses in the BLA.

\section{Spatial and temporal profile of VAB-evoked responses in the $B L A$}

To obtain information regarding the nature and localization of VAB-evoked responses in the BLA, seven rats were used to map field potentials and multiple-unit clusters in the BLA evoked by VAB stimulation. Data from a representative electrode penetration are displayed in Figure 2. As shown in Figure 2, $A$ and $B$, 

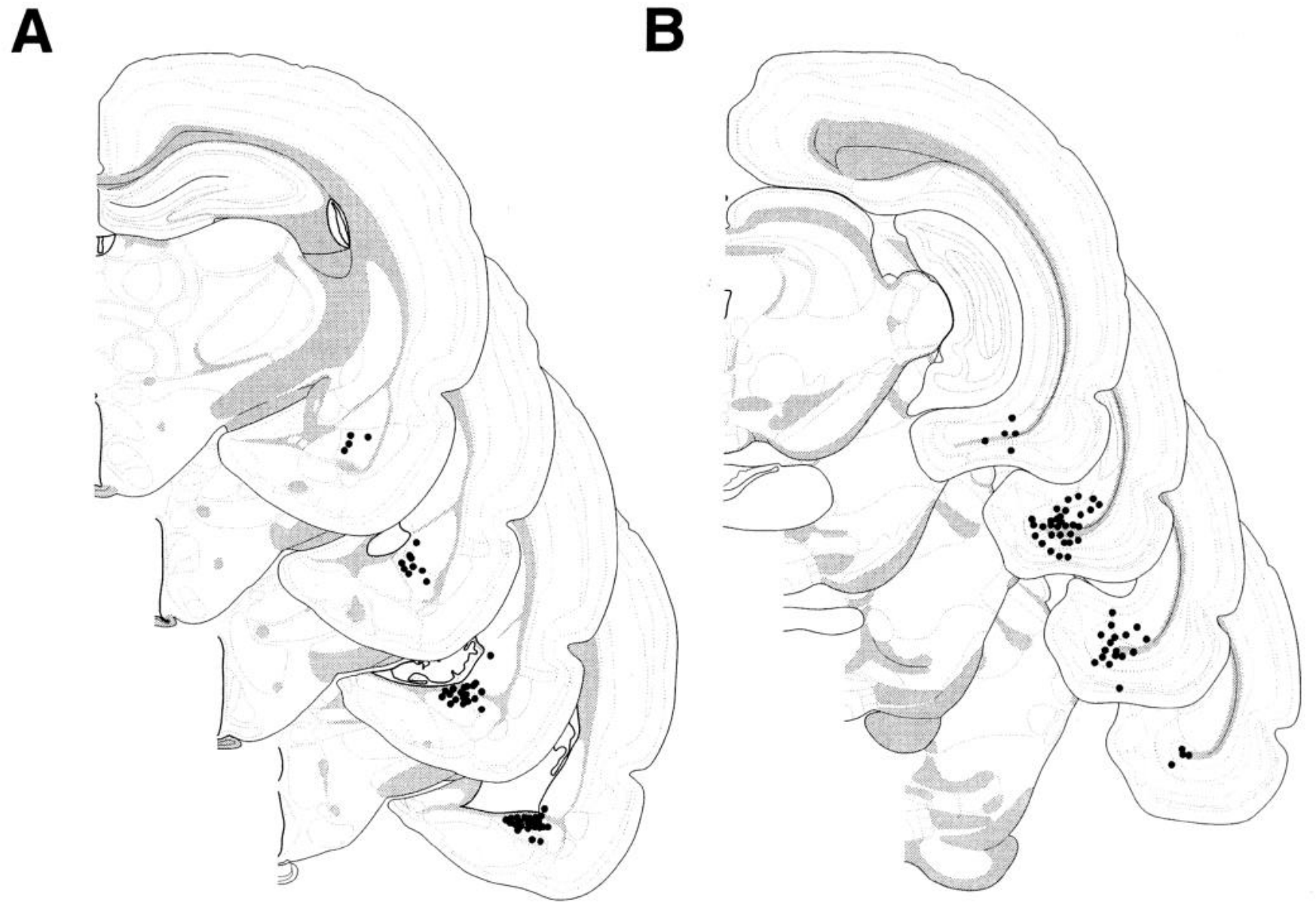

Figure 1. Schematic diagram of recording electrode placement in the basolateral amygdala (BLA) and hippocampal formation (HF). The electrode placements were obtained from a histological examination of brain sections from 59 of the 76 rats used for electrophysiological recordings. A, Recording electrode placements (solid circles) were concentrated in the posterior division of the BLA; most placements were located in the posterior basolateral and basomedial nuclei. B, Stimulating electrode placements (solid circles) were concentrated in the ventrocaudal HF, specifically in the ventral subiculum, lateral entorhinal cortex, and VAB.

the recording electrode passed through the full dorsal-ventral extent of the posterior division of the BLA; the stimulating electrode was localized in the VAB. The field potentials and multiple-unit clusters evoked at $200 \mu \mathrm{M}$ steps along the electrode track are shown in Figure 2C. At dorsal levels of the BLA, the evoked field potential consisted of a negative-positive waveform, with the negative component $\left(N_{1}\right)$ exhibiting a shorter latency than the positive component $\left(P_{1}\right)$. This response pattern was maintained through the majority of BLA recording sites. However, as the electrode passed out of the BLA the field potential reversed polarity, suggesting that the current source was in the BLA. Evoked multiple-unit clusters were observed at several of the recording sites. In general, peak multiple-unit firing corresponded with the peak negativity of the field potential. This pattern of results was true for both the temporal and spatial profiles of unit discharge. That is, the peak negativity of the field potential was maximal from $200-800 \mu \mathrm{M}$ along the electrode track, a region where the density of evoked multiple-unit activity was greatest. Furthermore, for any given point along this region of the electrode track, $N_{1}$ latency corresponded well with the latency of unit discharge. This is illustrated in Figure 3, which shows the significant correlation $[r(10)=0.95, p<$ $0.0001]$ between $N_{1}$ latency and the latency of peak unit firing in 12 rats.
The spatial and temporal correlation of both $N_{1}$ amplitude and $N_{1}$ latency with unit firing suggests that the peak of the negative wave is a population correlate of VAB-evoked spike firing in the amygdala. In other words, $N_{1}$ appears to contain a "population spike," a field potential generated by synchronous action potential discharge. The latency of the BLA population spike and associated unit firing is consistent with a monosynaptic projection from the $\mathrm{HF}$ and agrees with values reported elsewhere (Mello et al., 1992a,b). As will be shown below, the slope of the negative-going phase of $N_{1}$ appears to provide a measure of VAB-evoked excitatory postsynaptic potentials (EPSPs) in the BLA that underlie the genesis of VAB-evoked spike firing. The mechanisms responsible for generating $P_{1}$ are less clear, but may involve feed-forward inhibitory postsynaptic potentials (IPSPs) generated in the BLA by HF stimulation (Mello et al., 1992a).

\section{Properties of VAB-evoked field potentials in the BLA}

In an effort to further characterize the properties of BLA field potentials, 12 rats were used for the collection of input-output functions and the examination of synaptic plasticity in response to paired-pulse stimulation and brief trains of HFS. The inputoutput functions were generated across two ranges of stimulation intensity: $20-200 \mu \mathrm{A}(n=9)$ and $200-2000 \mu \mathrm{A}(n=3)$. For each rat, three responses were collected at each intensity ( $10 \mathrm{sec}$ 


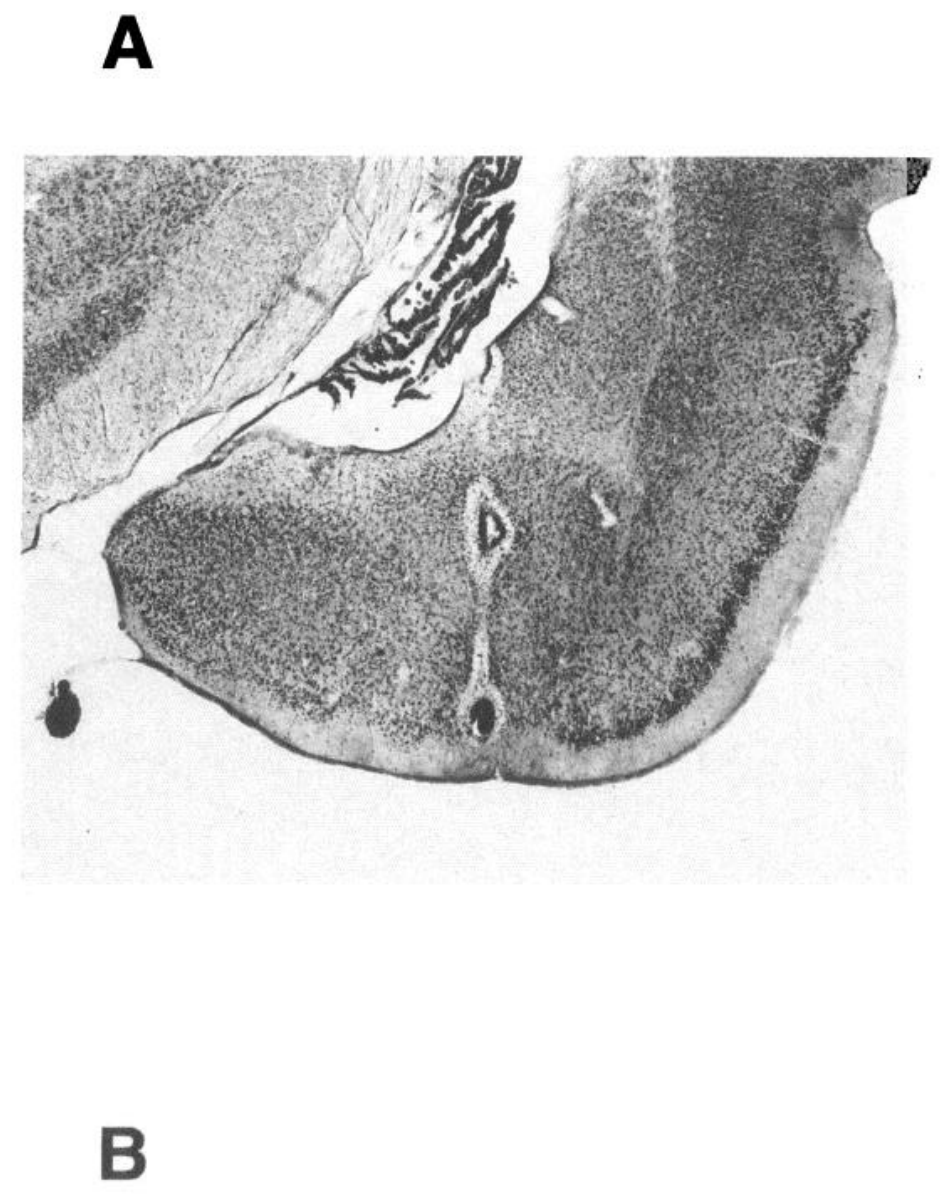

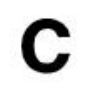

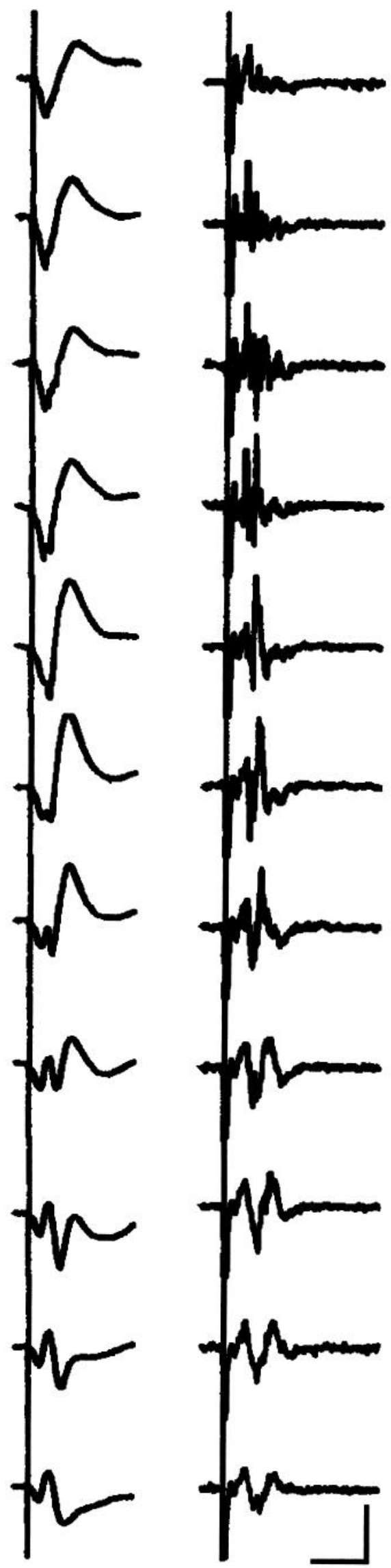

Figure 2. Spatial profile of ventral angular bundle (VAB)-evoked responses in the BLA of a representative rat. A, Photomicrograph showing the recording electrode track through the posterior division of the BLA. $B$, Photomicrograph showing the stimulating electrode placement. $C$, VAB- 

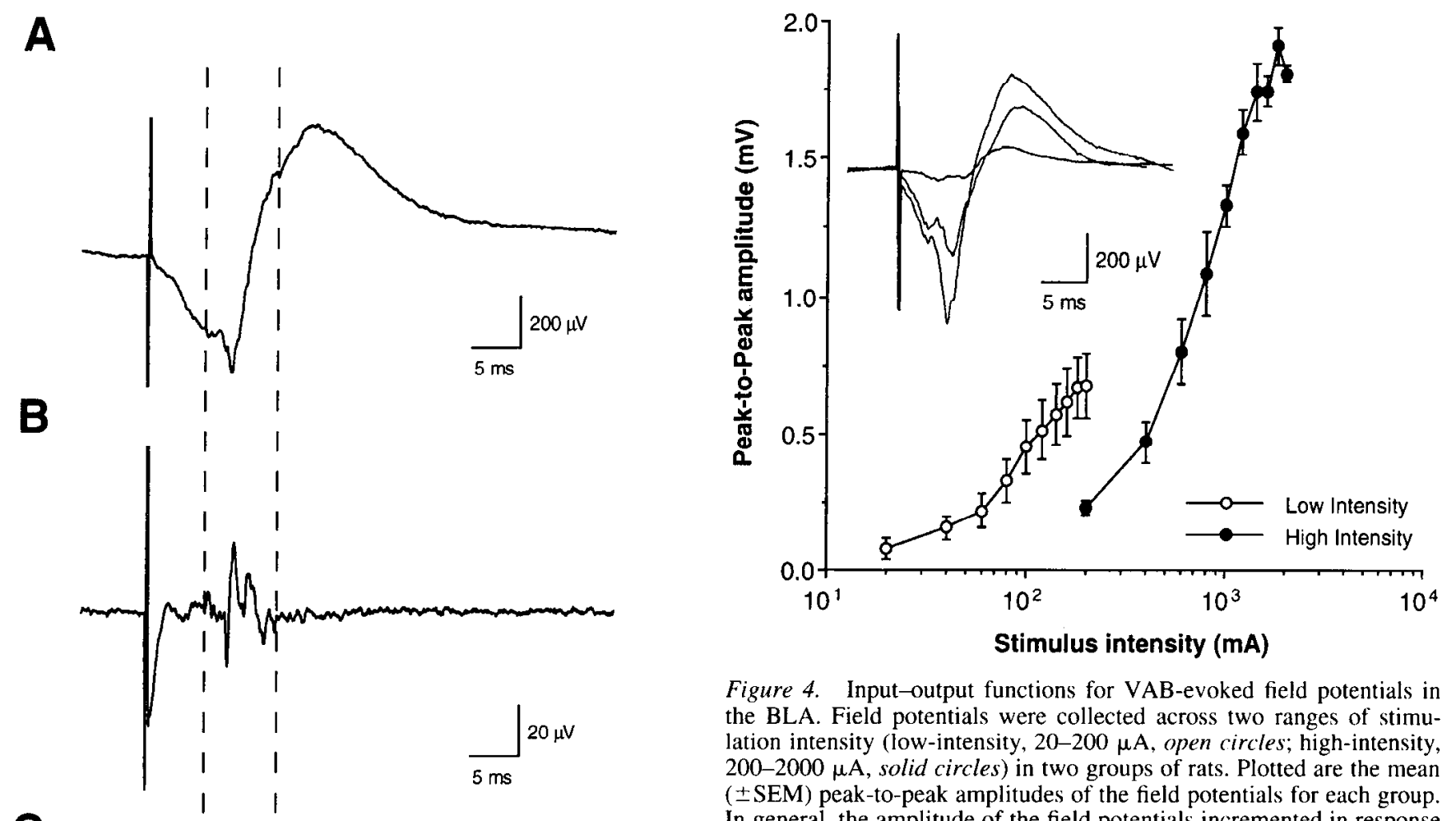

Figure 4. Input-output functions for VAB-evoked field potentials in the BLA. Field potentials were collected across two ranges of stimulation intensity (low-intensity, $20-200 \mu \mathrm{A}$, open circles; high-intensity, $200-2000 \mu \mathrm{A}$, solid circles) in two groups of rats. Plotted are the mean ( \pm SEM) peak-to-peak amplitudes of the field potentials for each group. In general, the amplitude of the field potentials incremented in response to increasing levels of stimulation and reached an asymptote at levels of stimulation $>1 \mathrm{~mA}$. Inset. Three superimposed field potentials evoked at three different stimulation intensities $(200,1000$, and 2000 $\mu \mathrm{A})$ in a high-intensity rat. Waveforms are an average of five evoked responses. Note the appearance of the sharp potential on the negative component of the waveform at the intermediate and high stimulation intensities.

of stimulation intensity, with maximal responses produced by relatively high levels of stimulation (1-2 mA). Not surprisingly, the input-output function was steeper with the higher range of stimulation intensities. Importantly, the responses saturated at high levels of stimulation indicating that they were not artifactual. An ANOVA with a between-subjects factor of range (two levels: low or high) and a within-subjects factor of intensity (10 levels) confirmed these impressions. The ANOVA revealed reliable main effects of both range $[F(1,10)=30.4, p<0.0005]$ and intensity $[F(9,90)=84.3, p<0.0001]$, and a significant interaction of the two $[F(9,90)=18.6, p<0.0001]$.

To examine the possibility that VAB-evoked field potentials Figure 3. Temporal correlation of VAB-evoked field potentials and BLA and the corresponding unit record $(B)$. Waveforms are an average of five evoked responses. The dashed lines were drawn to emphasize the correlation between the peak negativity of the field potential $\left(N_{1}\right)$ and unit discharge. $C$, Linear correlation between spike latency and $N_{1}$ latency in 12 rats. The Pearson correlation coefficient is displayed in the graph.

between stimuli) and an average was computed. The mean input-output functions from all the rats are shown in Figure 4. It is apparent from these curves that the amplitude of the field potentials (represented as peak-to-peak amplitude) is a function exhibit synaptic plasticity, two procedures that are known to increase presynaptic neurotransmitter release were employed in a subset of the input-output subjects $(n=7)$. The first involved applying paired stimulus pulses to the VAB and the second involved applying short trains of HFS to the VAB. For the pairedpulse studies, stimulus pairs were delivered at a fixed intensity (mean $=500 \mu \mathrm{A}$ ) and varied according to their interstimulus interval (ISI). Ten ISIs were used that ranged from $10-100 \mathrm{msec}$ (10 msec steps). Three pairs of stimuli were delivered at each ISI (10 sec between pairs) and an average computed; the entire

evoked field potentials and multi-unit clusters in the BLA at $200 \mu \mathrm{M}$ intervals along the recording electrode track in $A$. VAB stimulation evoked a biphasic waveform, the negative component of which was spatially correlated with evoked unit activity. VAB-evoked responses were maximal 1 $\mathrm{mm}$ into the penetration, a region corresponding to the posterior basolateral nucleus. Note that the VAB-evoked field potentials reversed in polarity as the electrode was passed out of the BLA. Waveforms are an average of five evoked responses. Calibration: $15 \mathrm{msec} ; 400 \mu \mathrm{V}$ (field potentials), $40 \mu \mathrm{V}$ (units). 
A

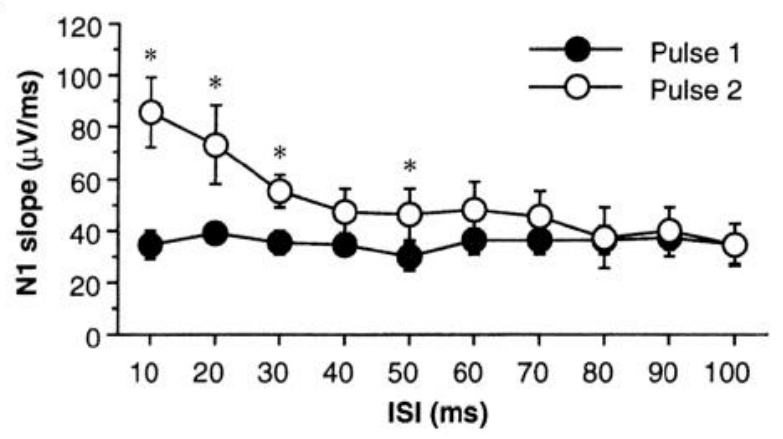

B

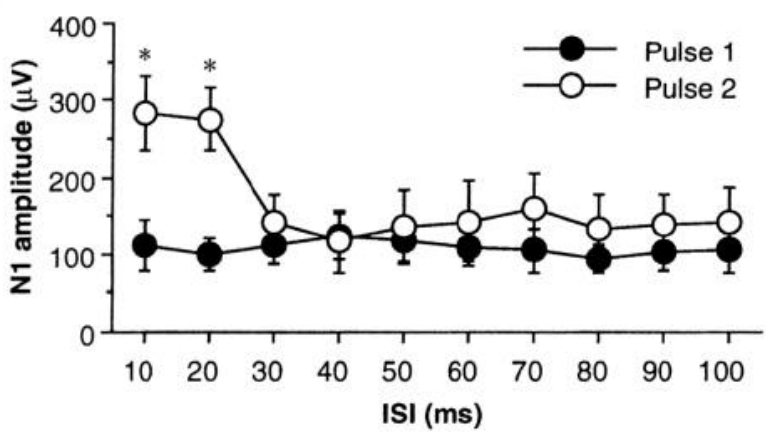

C

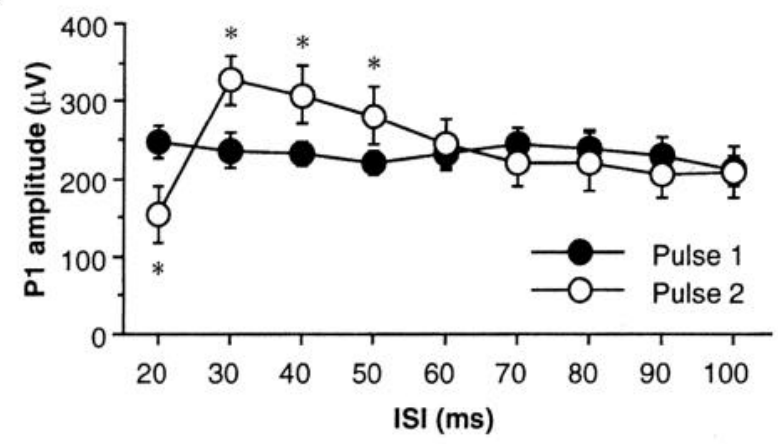

Figure 5. Paired-pulse plasticity of VAB-evoked field potentials in the BLA. Values represent the mean $( \pm \operatorname{SEM})(A) N_{1}$ slope, $(B) N_{1}$ amplitude, and $(C) P_{1}$ amplitude of field potentials evoked by each pulse (pulse 1, solid circles; pulse 2, open circles) of the series of interstimulus intervals (ISIs). Paired-pulse plasticity was expressed differently for the two response components. Facilitation was the predominant response of $N_{1}$ slope and $N_{1}$ amplitude at short ISIs (10-50 msec). In contrast, $P_{1}$ exhibited depression at the short ISI $(20 \mathrm{msec})$ and facilitation at intermediate ISIs $(30-50 \mathrm{msec})$. Asterisks indicate significant $(p<0.05)$ comparisons between pulse 1 and pulse 2 .

series was performed in an ascending fashion, from short to long ISIs. As shown in Figure $5 A-C$, BLA field potentials exhibited robust paired-pulse plasticity, an effect that was evident in the ANOVAs as a significant interaction between pulse number (two levels: first or second pulse) and ISI (nine levels: $20-100 \mathrm{msec}$ intervals) in the analyses of $N_{1}$ slope $[F(9,54)=5.3, p<$ $0.0001], N_{1}$ amplitude $[F(9,54)=10.9, p<0.0001]$, and $P_{1}$ amplitude $[F(8,48)=7.5, p<0.0001]$. Planned comparisons $(p<0.05)$ indicated that the nature of this paired-pulse plasticity was expressed differently in the positive and negative components of the field potentials. That is, short ISIs $(10-20 \mathrm{msec})$ produced a robust facilitation of $N_{1}$ and they produced a marginal inhibition of $P_{1}$. In contrast, longer ISIs (30-50 msec) produced a modest facilitation of both $N_{1}$ and $P_{1}$. PPF of $N_{1}$ am-

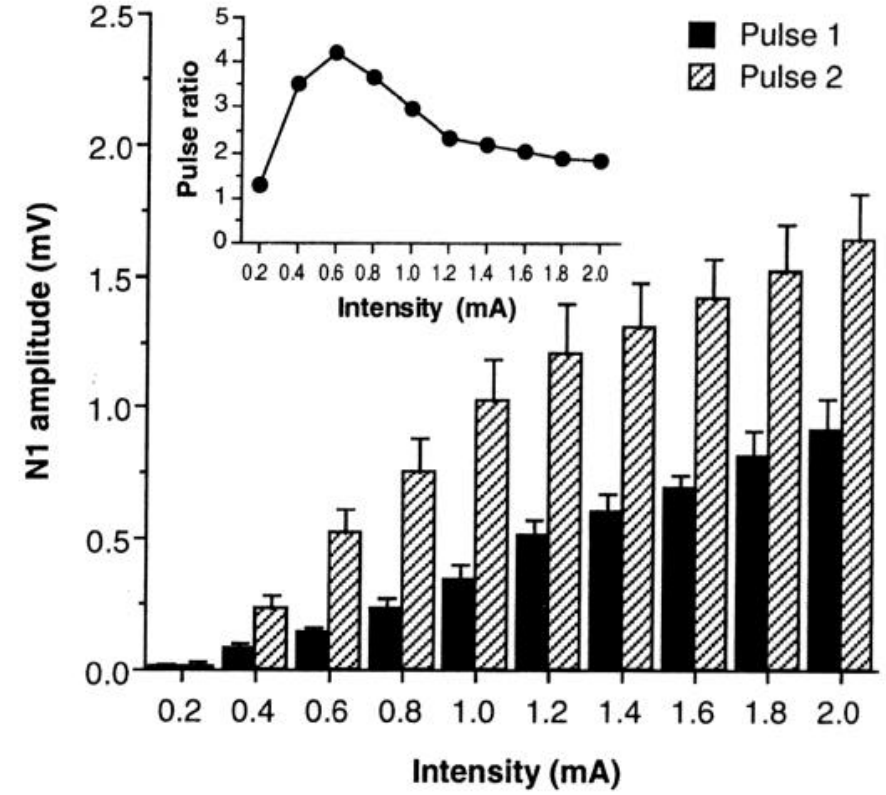

Figure 6. Input-output function for paired-pulse facilitation (PPF) of VAB-evoked field potentials in the BLA. Values represent the mean ( \pm SEM) $N_{1}$ amplitude for responses evoked by each pulse (pulse 1 , solid bars; pulse 2, hatched bars) of the series of pulse-pairs for 10 levels of VAB stimulation intensity. The ISI was $20 \mathrm{msec}$ for all stimulation intensities. All intensities except for $200 \mu \mathrm{A}$ were associated with reliable PPF. Inset, The inset shows the mean pulse ratios for each of the 10 stimulation intensities. There was a clear curvilinear relationship between PPF and stimulus intensity; optimal PPF was produced by intermediate stimulus intensities.

plitude was not graded, that is, it was present at the shortest ISIs (10-20 msec), but disappeared abruptly at the $30 \mathrm{msec}$ ISI. This suggests that PPF of $N_{1}$ amplitude may be due to a short-lived shift in the threshold for spike firing brought about by the first pulse in the pair. In contrast to $N_{1}$ amplitude, PPF of $N_{1}$ slope was graded as is typical of PPF at synapses in other neural circuits (Racine et al., 1983). This provides evidence that $N_{1}$ slope reflects a synaptic component of HF-BLA synaptic transmission. Because PPF is maximum at $10-20 \mathrm{msec}$ ISIs in which the second pulse occurs during $P_{1}$, it is unlikely that $P_{1}$ is a reflection of a population IPSP as suggested earlier.

An additional series of rats $(n=5)$ examined the relationship between PPF ( $20 \mathrm{msec}$ ISI) and VAB stimulation intensity. As shown in Figure 6, PPF was dependent on stimulation intensity. This was evident as a reliable interaction of pulse number (two levels: first or second pulse) and stimulus intensity (10 levels: $200-2000 \mu \mathrm{A}$ in $200 \mu \mathrm{A}$ steps $)$ in the ANOVA $[F(9,36)=$ 20.9, $p<0.0001]$ of $N_{1}$ amplitude. Planned comparisons $(p<$ 0.05 ) indicated that significant paired pulse facilitation was apparent at all stimulation intensities except $200 \mu \mathrm{A}$. As shown in the inset of Figure 6, PPF was curvilinearly related to stimulation intensity; optimal PPF was generated with stimulus intensities $(400-1200 \mu \mathrm{A})$ that produced submaximal field potentials. The same pattern of results was obtained in the analysis of $N_{1}$ slope (data not shown). This indicates that paired-pulse plasticity at HF-BLA synapses is dependent on the number of afferents activated by the initial stimulus pulse.

To further assess short-term synaptic plasticity at HF-BLA synapses, we examined the response of BLA neurons to brief trains of HFS in the same rats $(n=7)$ used in the initial pairedpulse studies. After collecting the paired-pulse data, the rats 
were administered 10 stimulus pulses at three frequencies: 50 , 100, and $400 \mathrm{~Hz}$. Again, three responses were collected at each frequency and averaged. These tests were performed for two reasons: (1) to examine if BLA field potentials exhibit frequency facilitation or depression and (2) to determine if there is an antidromic component to VAB-evoked field potentials in the BLA (antidromic, hut not orthodromic, responses respond to $400 \mathrm{~Hz}$ stimulation). Of the seven rats tested, seven followed $50 \mathrm{~Hz}$ stimulation, four followed $100 \mathrm{~Hz}$ stimulation, and zero followed $400 \mathrm{~Hz}$ stimulation (nonfollowers only responded on the first pulse of the train). The absence of response to $400 \mathrm{~Hz}$ stimulation indicates that VAB-evoked field potentials are orthodromic, and the ability of the majority of the subjects to follow 50 or $100 \mathrm{~Hz}$ stimulation is consistent with a monosynaptic HFBLA projection. Figure $7 A$ shows representative averaged field potential responses to 50 and $100 \mathrm{~Hz}$ stimulation frequencies. As predicted from the paired-pulse experiments, BLA field potentials exhibited frequency facilitation at both 50 and $100 \mathrm{~Hz}$ (Fig. $7 B$ ). Separate ANOVAs indicated a reliable main effect of pulse number (five levels for $50 \mathrm{~Hz}$ data and 10 levels for 100 $\mathrm{Hz}$ data) for the $N_{1}$ amplitude of responses evoked by $50 \mathrm{~Hz}$ [ $n$ $=7 ; F(4,24)=10.1, p<0.0001]$ and $100 \mathrm{~Hz}$ trains $[n=4$; $F(9,27)=6.1 . p<0.0002$ ]. A similar pattern of results was obtained in the analysis of $N_{1}$ slope (data not shown). Collectively, these results suggest that BLA field potentials are sensitive to manipulations that are known to increase neurotransmitter release in other neural circuits.

\section{Effects of lidocaine on VAB-evoked field potentials in the BLA}

The foregoing results suggest that BLA field potentials represent an extracellular correlate of monosynaptic transmission and neuronal firing in the HF-BLA projection. Although the correlation of the field potentials and multiple-unit firing suggests that the field potentials are generated within the BLA, it remains possible that they are generated in some distal brain site and volumeconducted to the BLA. To test this possibility, we infused $4 \%$ lidocaine $\mathrm{HCl}$ (a local anesthetic) into the $\mathrm{BL} \Lambda$ while recording VAB-evoked field potentials. As shown in Figure $8 A-C$, lidocaine infusion reversibly attenuated both the negative and positive components of BLA field potentials relative to saline controls. ANOVAs performed on the data revealed a significant main effect of group [two levels: saline or lidocaine; $F(1,8)=$ $8.1, p<0.03]$ and a significant interaction of group and postinfusion block [six 10 min blocks; $F(5,40)=4.1, p<0.005$ ] for $N_{1}$ amplitude, a significant interaction of group and block $[F(5$, $40)=3.9, p<0.006]$ for $N_{1}$ slope, and a significant interaction of group and block for $P_{1}$ amplitude $[F(5,40)=5.8, p<$ $0.0005]$. Planned comparisons $(p<0.05)$ indicated that the responses in the lidocaine-treated rats were attenuated for the first two 10 min blocks following drug infusion, and returned to baseline thereafter. For a particular response measure, there was considerable variability in the effect of lidocaine. For example, the attenuation of $N_{1}$ slope ranged from 60 to $100 \% 5 \mathrm{~min}$ after lidocaine infusion. This variability could have arisen from a number of factors including the efficacy of the infusion, the extent of drug diffusion, and the proximity of the recording/infusion site to the lateral ventricle. In cases where lidocaine did not completely abolish the response, it is assumed that one of these factors accounted for the incomplete attenuation. In general, these results support the vicw that BLA ficld potentials require local neuronal activity in the amygdala for their expression.
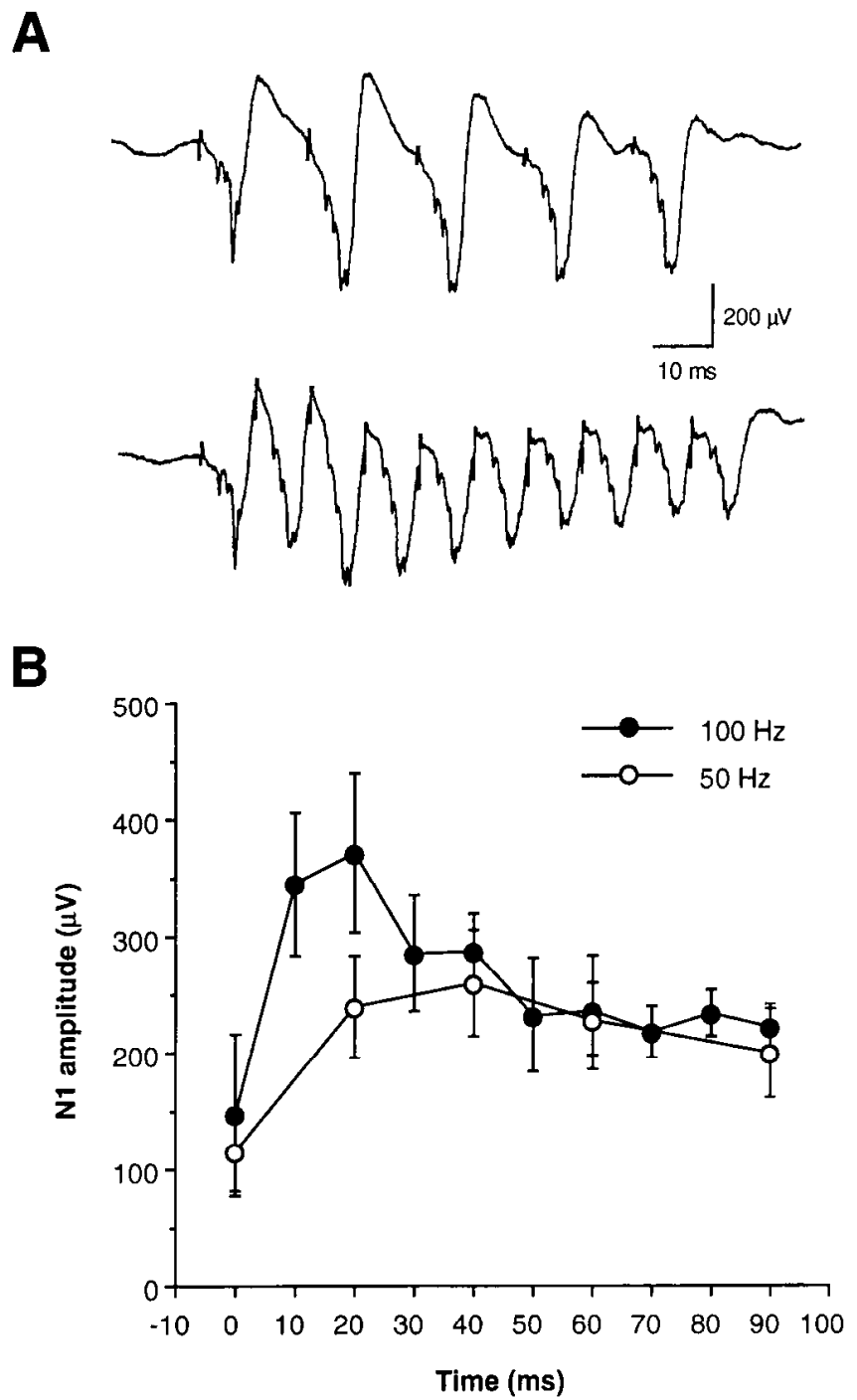

Figure 7. Effects of brief trains of high-frequency stimulation (HFS) on VAB-evoked responses in the BLA. A. Representative BLA field potentials evoked by $100 \mathrm{msec}$ trains of $50 \mathrm{~Hz}(t o p)$ and $100 \mathrm{~Hz}$ (bot$t o m)$ VAB stimulation. Waveforms are an average of five evoked responses. Both frequencies of HFS produced facilitation of $N_{1}$ amplitude, which is shown graphically in $B . B$. Mean $\left( \pm\right.$ SEM) $N_{1}$ amplitude for the field potentials evoked by 50 (solid circles) and $100 \mathrm{~Hz}$ (open circles) stimulation. Both frequencies of stimulation produced substantial frequency facilitation that persisted for the duration of the train. The facilitation produced by $100 \mathrm{~Hz}$ stimulation was greater than that produced by $50 \mathrm{~Hz}$ stimulation.

\section{Effects of glutamate receptor antagonists on VAB-evoked field potentials in the BLA}

It has previously been suggested that HF projections to the BLA are glutamatergic (Mello et al., 1992b). To test this possibility. we infused either 6,7-dinitro-quinoxaline-2.3-dione (10) $\mathrm{mM}$ DNQX; $n=6)$, D,L-2-amino-5-phosphonovalerate $(100 \mathrm{mM}$ APV; $n=6$ ), or vehicle ( $0.9 \%$ saline or $100 \%$ DMSO, $n=6$ ) into the BLA during recording. As shown in Figure 9A, DNQX, but not APV, attenuated the slope of the negative component of BLA field potentials. This attenuation of $N_{1}$ slope by DNQX was nearly complete. An ANOVA with factors of group (three levels: vehicle, APV, or DNQX) and postinfusion block (six 10 min blocks) yielded a reliable main effect of group $[F(2,15)=$ 13.5, $p<0.0005$ ] for $N_{1}$ slope. Planned comparisons $(p<0.05)$ 
A
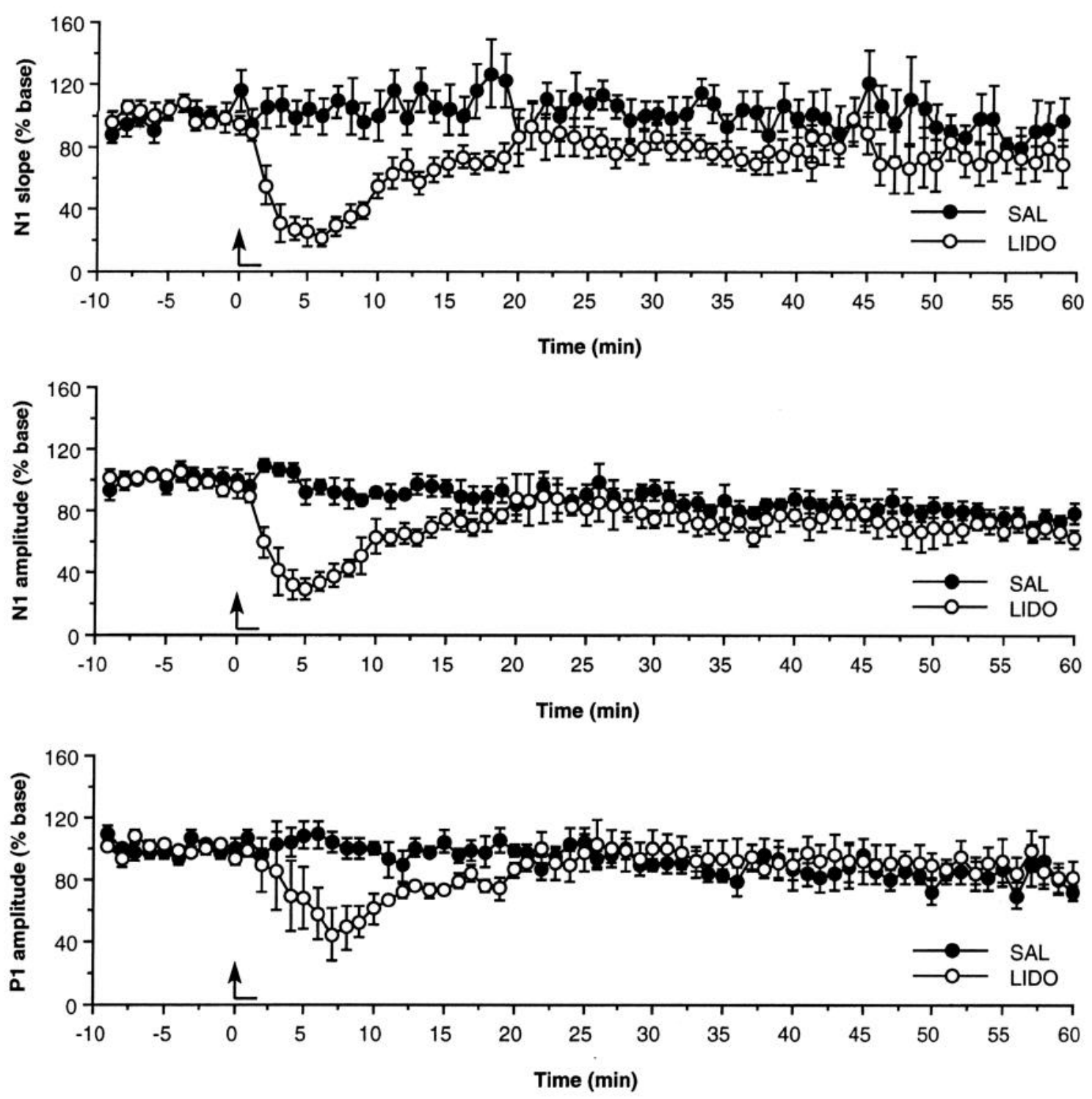

Figure 8. Effects of lidocaine on VAB-evoked field potentials in the BLA. Mean ( \pm SEM) percentage of baseline for $(A) N_{1}$ slope, $(B) N_{1}$ amplitude, and $(C) P_{1}$ amplitude of field potentials evoked by VAB stimulation in rats receiving either saline (solid circles) or lidocaine (open circles) infusions. The onset and duration of the infusion are indicated by the arrow. All measured were severely attenuated by lidocaine infusion. This effect was temporary and the field potentials returned to their baseline amplitude approximately 20 min following lidocaine infusion. There was no effect of saline infusion on the field potentials.

indicated that rats treated with DNQX were reliably different from those treated with either APV or vehicle, which were not different from each other. As shown in Figure 9B, both APV and DNQX attenuated $N_{1}$ amplitude; responses in APV-treated rats recovered approximately $20 \mathrm{~min}$ following infusion and responses in DNQX-treated rats did not recover. An ANOVA with factors of group (three levels: vehicle APV, or DNQX) and postinfusion block (six 10 min blocks) yielded a reliable main effect of group $[F(2,15)=39.2, p<0.0001]$ and a reliable interaction of group and block $[F(10,75)=3.7, p<0.0005]$ for $N_{1}$ amplitude. Planned comparisons $(p<0.05)$ indicated that APV attenuated $N_{1}$ for the first two 10 min blocks, whereas DNQX attenuated the field potentials for the entire recording period. As shown in Figure $9 C$, APV also reversibly attenuated $P_{1}$ amplitude. In contrast, DNQX did not reliably affect $P_{1}$ amplitude.
This was evident in an ANOVA as a significant interaction between group and block $[F(10,75)=5.0, p<0.0001]$; planned comparisons $(p<0.05)$ indicated that APV, but not DNQX, attenuated BLA field potentials for three 10 min blocks following infusion. These data reveal that VAB-evoked field potentials in the BLA are mediated by both AMPA and NMDA receptors, and that these receptors mediate different components of the field potentials. Specifically, $N_{1}$ slope appears to be almost entirely AMPA receptor-mediated as DNQX produced a nearly complete abolition of the response. In contrast, $N_{1}$ amplitude has both AMPA and NMDA receptor-dependent components; DNQX and APV produced incomplete attenuations of the response that, if combined, account for the entire response. Lastly, $P_{1}$ amplitude has a modest NMDA receptor-mediated component that cannot account for the entire response. The neurotransmitter 


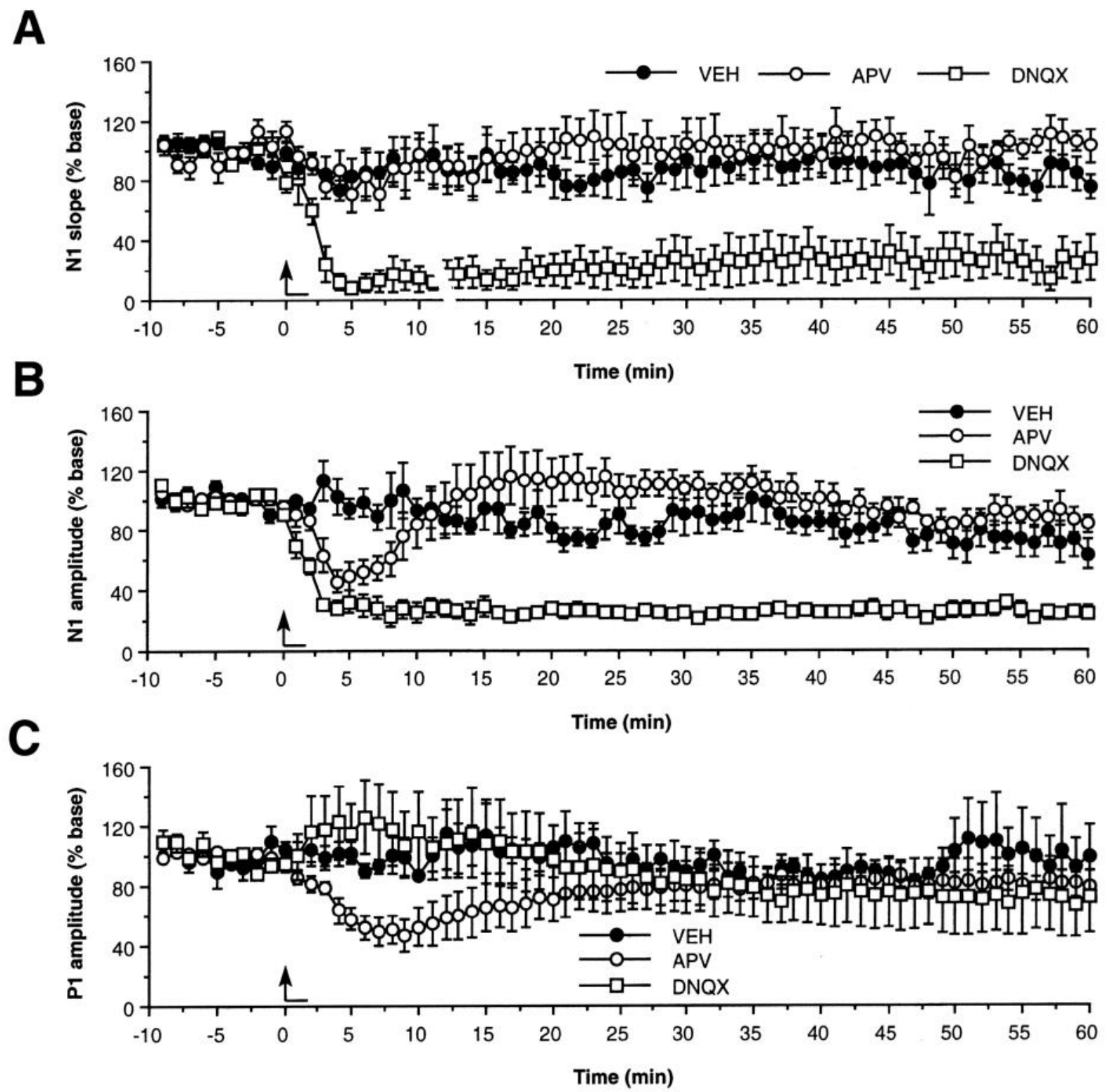

Figure 9. Effects of glutamate receptor antagonists on VAB-evoked field potentials in the BLA. Mean ( \pm SEM) percentage of baseline for $(A) N_{1}$ slope, $(B) N_{1}$ amplitude, and $(C) P_{1}$ amplitude of field potentials evoked by VAB stimulation in rats receiving either vehicle (solid circles), D, $\mathrm{L}-2-$ amino-5-phosphonovalerate ( $A P V$, open circles), or 6,7-dinitro-quinoxaline-2,3-dione (DNQX, open squares) infusions. The onset and duration of the infusion are indicated by the arrow. $N_{1}$ slope and $N_{1}$ amplitude were irreversibly attenuated by DNQX infusion; DNQX did not effect $P$ amplitude. In contrast, both $N_{1}$ amplitude and $P_{1}$ amplitude were attenuated by APV infusion. As with lidocaine, this effect was reversible; field potentials returned to baseline approximately 20 min following APV infusion. There was no effect of vehicle infusion on the field potentials.

receptor(s) responsible for the APV-insensitive component of $P_{1}$ is not known.

\section{Long-term synaptic plasticity of VAB-evoked field potentials in the BLA}

To examine the possibility that HF-BLA synaptic transmission is modifiable, short trains of HFS were delivered to the VAB. Figure 10 shows the mean amplitude and slope of $N_{1}$ for three groups of rats. After $10 \mathrm{~min}$ of baseline recording, rats received either 200 pulses at $100 \mathrm{~Hz}$ (HFS-100 Hz, $10200 \mathrm{msec} 100 \mathrm{~Hz}$ bursts, $n=6$ ), test pulses alone (LFS- $0.05 \mathrm{~Hz}, n=6$ ), or 200 pulses at $1 \mathrm{~Hz}$ (LFS-1 Hz, $n=6$ ). These stimulation events were presented four times at $5 \mathrm{~min}$ intervals. In comparison to animals receiving LFS $(0.05 \mathrm{~Hz})$, HFS produced a marked and enduring increase in the slope and amplitude of $N_{1}$, and LFS ( 1 $\mathrm{Hz}$ ) produced a moderate and transient depression of these responses; field potentials in rats receiving low-frequency test pulses remained stable across the recording session. An ANOVA with factors of group (three levels: HFS-100 Hz, LFS-0.05 Hz, or LFS-1 Hz) and poststimulation block (six 10 min blocks) revealed a significant main effect of group $[F(2,15)=31.7, p$ $<0.0001]$ and a significant interaction of group and block $[F(10,75)=6.6, p<0.0001]$ for $N_{1}$ amplitude and a significant main effect of group $[F(2,15)=17.0, p<0.0001]$ and a significant interaction of group and block $[F(10,75)=22.4, p<$ $0.0001]$ for $N_{1}$ slope. Planned comparisons $(p<0.05)$ indicated that HFS augmented $N_{1}$ slope and $N_{1}$ amplitude for the entire poststimulation period, whereas $1 \mathrm{~Hz}$ LFS depressed $N_{1}$ ampli- 
tude for the first two 10 min poststimulation blocks; $N_{1}$ slope was not different in the two LFS groups. The enduring enhancement of BLA field potentials by HFS was only evident in $N_{1}$; planned comparisons $(p<0.05)$ following a reliable ANOVA |group $\times$ block interaction; $F(10,75)=2.9, p<0.005]$ indicated that $P_{1}$ showed only a transient augmentation for the first two 10 min poststimulation blocks relative to LFS controls (data not shown).

For a within-subjects assessment of LTP in HFS subjects, responses collected in the $10 \mathrm{~min}$ post-HFS blocks were compared to those collected during the $10 \mathrm{~min}$ baseline. One-way ANOVAs with factors of 10 min block (seven levels: baseline and six post-HFS blocks) computed on the non-normalized data indicated that $N_{1}$ slope $[F(6,30)=56.4, p<0.0001], N_{1}$ amplitude $[F(6,30)=35.0, p<0.0001]$, and $P_{1}$ amplitude $[F(6,30)$ $=9.4, p<0.0001]$ varied across the $10 \mathrm{~min}$ blocks. Planned comparisons $\left(\mu<0.05\right.$ ) indicated that $N_{1}$ slope was significantly greater than baseline in all post-HFS blocks, $N_{1}$ amplitude was elevated above baseline in the first four 10 min blocks, and $P_{1}$ amplitude was reliably lower than baseline in the last three 10 min blocks. Thus, only the negative component of the VABevoked field potential exhibited LTP. The induction of LTP occurred in all of the subjects; LTP was maintained through the $60 \mathrm{~min}$ post-HFS recording period in four of the six rats. In addition to exhibiting LTP, the $N_{1}$ component appeared to exhibit posttetanic potentiation (PTP), a short-term enhancement in synaptic transmission that decays within 5-10 min of HFS. As shown in Figure 10. PTP was most pronounced for $N_{1}$ amplitude.

To test the NMDA receptor dependence of BLA LTP, APV was infused into the amygdala before the delivery of a single HFS train. A within-subjects design was used to compare postHFS responses with pre-HFS responses collected before APV infusion. As shown in Figure 11, IIIS did not augment either $N_{1}$ slope or $N_{1}$ amplitude following APV infusion. A withinsubjects ANOVA with a factor of $10 \mathrm{~min}$ block (three levels: baseline and two post-HFS blocks) indicated that $N_{1}$ amplitude $[F(2,4)=10.3, p<0.03]$, but not $N_{1}$ slope $[F(2,4)=1.2, p$ $=0.38]$, varied significantly across the recording period. Planned comparisons $\left(p<0.05\right.$ ) revealed that $N_{1}$ amplitude was reliably depressed in both post-HFS blocks compared to the predrug baseline. This selective depression of $N_{1}$ amplitude was expected given the effects of APV reported above, although the relatively stable depression of $N_{1}$ amplitude in the post-HFS period was not anticipated given the rapid recovery of APV attenuation observed earlier. It may be the case that delivering HFS in the presence of APV produced an enduring depression of BLA spike firing, as would be predicted by some Hebbian covariance models.

At several synapses, both short- and long-tcrm forms of synaptic plasticity have been shown to involve changes in the levels of presynaptic neurotransmitter release (Zucker, 1989). At hippocampal synapses, brief trains of HFS like those used here produce a presynaptically mediated PTP. In some brain areas, such as in hippocampal area $\mathrm{CA}_{3}$, PTP is followed by a LTP that is mediated by an increase in presynaptic neurotransmitter release (Zalutsky and Nicoll, 1990); LTP at synapses in hippocampal area $\mathrm{CA}_{1}$ and the dentate gyrus may involve both increases in transmitter release and postsynaptic glutamate receptors (Maren and Baudry, 1995). It is of considerable interest to determine whether synaptic plasticity at BLA synapses is mediated by an increase in presynaptic neurotransmitter release. One method for determining if changes in transmitter release are associated with LTP is to examine PPF before and after LTP induction (e.g., Zalutsky and Nicoll, 1990). Because PPF is known to be mediated at the presynaptic terminal, a manipulation that interacts with PPF can also be assumed to have a presynaptic locus.

To assess the relationship between PPF and LTP at BLA synapses, paired pulses ( $20 \mathrm{msec}$ ISI) were substituted for the standard single test pulses in a 70 min recording session. During this recording session, a $10 \mathrm{~min}$ baseline of field potentials was collected and followed by the induction of LTP (10 200) msec $100 \mathrm{~Hz}$ bursts); responses were collected $60 \mathrm{~min}$ following LTP induction. Figure 12 shows 10 min means for $N_{1}$ slope (percentage of baseline) and the magnitude of PPF (ratio of slopes from pulse 2 and pulse 1 ) across the recording session. As shown, HFS induced an initial PTP and subsequent LTP of $N_{1}$ slope that persisted for the duration of the $60 \mathrm{~min}$ recording session [main effect of $10 \mathrm{~min}$ block; $F(6,30)=6.3, p<$ 0.0005]. The induction of LTP was associated with a significant reduction in the magnitude of PPF which persisted for the du ration of the recording session (main effect of 10 min block: $F(6,30)=6.3, p<0.0005]$. Planned comparisons $(p<0.05)$ indicated that the decrease in PPF occurred at all post-HFS intervals, but was greatest in the first interval, which corresponds to the interval at which PTP is expressed. A similar pattern of results was obtained for $N_{1}$ amplitude (data not shown). One might argue that the decrease in PPF observed following LTP induction is due to a rightward shift in the function relating the amplitude of the first pulse of the pulse-pair and the magnitude of paired-pulse plasticity (see Fig. 6, inset). However, we tested two rats in which the post-LTP response was equated to that evoked before LTP. Despite similar first-pulse slopes, responses evoked before LTP induction displayed greater PPF than those evoked after LTP induction. These results suggest that both PTP and LTP at HF-BLA synapses are associated with an increase in presynaptic neurotransmitter release.

\section{Involvement of the HF and BLA in Pavlovian fear conditioning}

The preceding results establish that an NMDA receptor-dependent LTP can be induced at HF-BLA synapses. It is tempting to speculate that this plasticity may be involved in the acquisition of contextual fear conditioning, which has been shown to involve NMDA receptor-dependent processes in the BLA (Fanselow and Kim, 1994). However, the role of BLA neurons and the ventrocaudal HF regions that project to the BLA (lateral entorhinal cortex, ventral subiculum) in contextual fear conditioning is not known. To examine the involvement of the HFBLA circuit in Pavlovian fear conditioning, either electrolytic lesions were made in the ventrocaudal HF or NMDA lesions were made in the BLA prior to fear conditioning.

A schematic depiction of the tissue damage obtained in rats with lesions is shown in Figure 13. Rats with electrolytic lesions in the ventrocaudal HF had extensive damage to the medial and lateral entorhinal cortex, ventral subiculum, and VAB. For the most part, the damage to ventral subiculum was complete, whereas damage to the entorhinal cortex was limited to more caudal areas. In some cases, there was damage to the caudal division of the dentate gyrus. In general, there was no damage to perirhinal cortex or rostral areas of the hippocampus. Rats with NMDA lesions intended for the amygdala possessed nearly complete lesions of the posterior divisions of the lateral, basolateral, and basomedial nuclei; the central nucleus and portions 


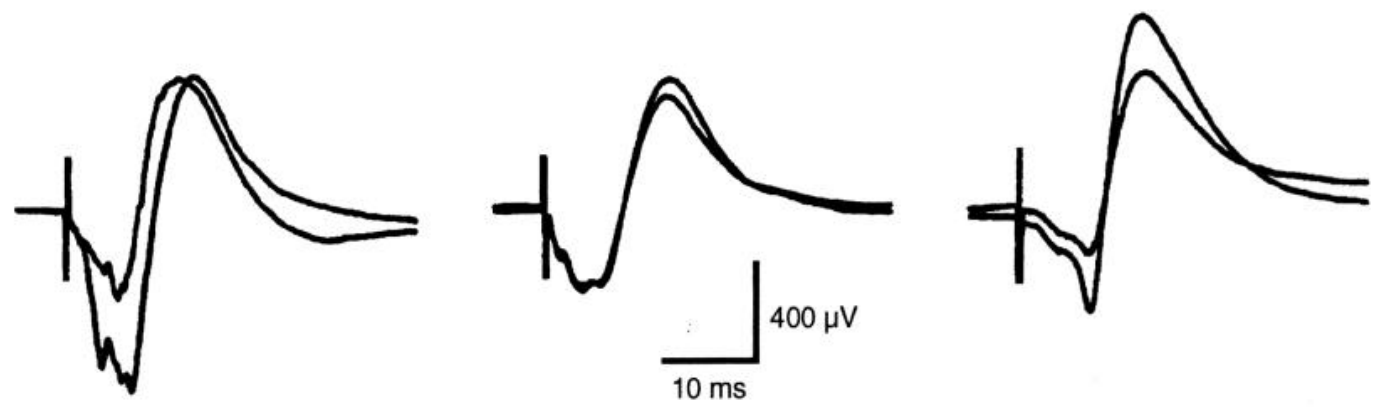

B

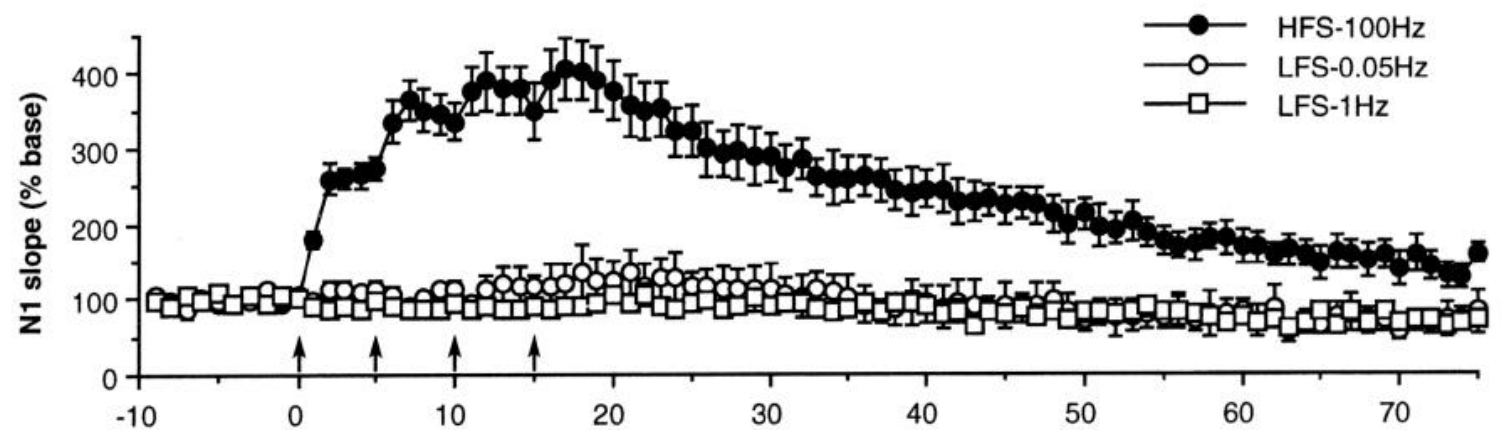

Time (min)

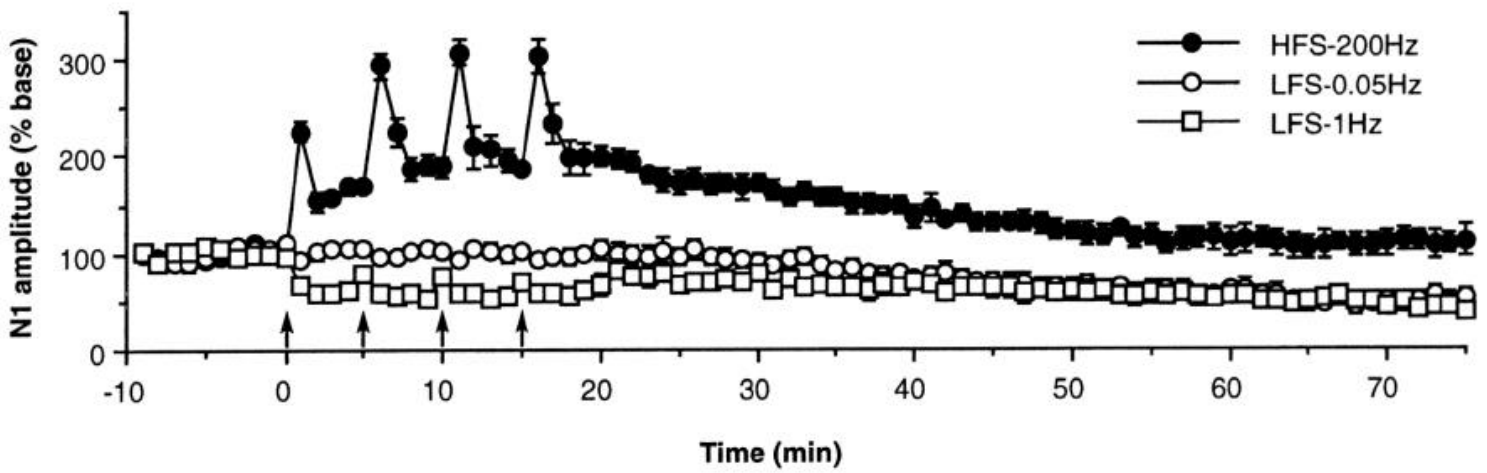

Figure 10. Long-term potentiation (LTP) of VAB-evoked field potentials in the BLA. A, Representative basolateral field potentials evoked before and after either high- or low-frequency stimulation (LFS). Pre- and poststimulation responses are superimposed. Leftmost traces are from a rat in the HFS- $200 \mathrm{~Hz}$ group (solid circles), the middle traces are from a rat in the LFS- $0.05 \mathrm{~Hz}$ group (open circles), and the rightmost traces are from a rat in the LFS-1 Hz group (open triangles). The waveforms are averages of 30 evoked responses collected either 10 min before the first stimulation session ( $\min -10$ to 0 ) or $10 \mathrm{~min}$ following the last stimulation session (min 15-25). HFS (leftmost traces) produced a marked LTP of VABevoked field potentials in the BLA, whereas LFS had either no effect on (middle traces) or produced a depression of (rightmost traces) the potentials. $B$. Mean $\left( \pm\right.$ SEM) percentage of baseline for $N_{1}$ slope and $(C) N_{1}$ amplitude during the 75 min recording period. For each subject, values represent $1 \mathrm{~min}$ averages computed from three evoked responses. Four sessions of stimulation were delivered at 5 min intervals and are indicated by the arrows. HFS produced an enduring LTP of HF-BLA synaptic transmission that persisted for the entire recording period following the last stimulation session. LFS $(1 \mathrm{~Hz})$ produced a modest, but reliable, depression of the $N_{1}$ amplitude of BLA field potentials that persisted for 20 min following the last stimulation session. Responses from all of the groups tended to decrease over the recording period, although the relative differences between the HFS and LFS groups were maintained despite this decrease.

of the anterior divisions of the basolateral and lateral nuclei were spared in all cases.

On the conditioning day, rats were placed in the observation chambers and given three tone-footshock pairings. Freezing during the three $64 \mathrm{sec}$ postshock periods on the conditioning day is shown in Figure 14. It is apparent that BLA, but not ventrocaudal HF lesions, eliminated the conditional freezing that occurs immediately following footshock (immediate postshock freezing). An ANOVA with factors of group (three levels: $\mathrm{SH}$, $\mathrm{HF}$, and $\mathrm{BL}$ ) and trial (three levels) revealed significant main effects of group $[F(2,32)=17.9, p<0.0001]$ and trial $[F(2$,
$64)=16.1, p<0.0001]$. Planned comparisons $(p<0.05)$ indicated that the rats with BLA lesions showed reliably less freezing than the other two groups following all three trials; rats with $\mathrm{HF}$ lesions did not differ from sham rats on any trial.

One and $2 \mathrm{~d}$ after conditioning the rats received "delayed" tests of conditional fear to the contextual cues of the conditioning chamber and the tone conditional stimulus, respectively. For the former, the rats were returned to the conditioning chamber for $8 \mathrm{~min}$ and, for the latter, the rats were placed in a novel context and presented the tone CS for $8 \mathrm{~min}$. Freezing to the contextual and tone CSs during the 8 min tests are shown in 

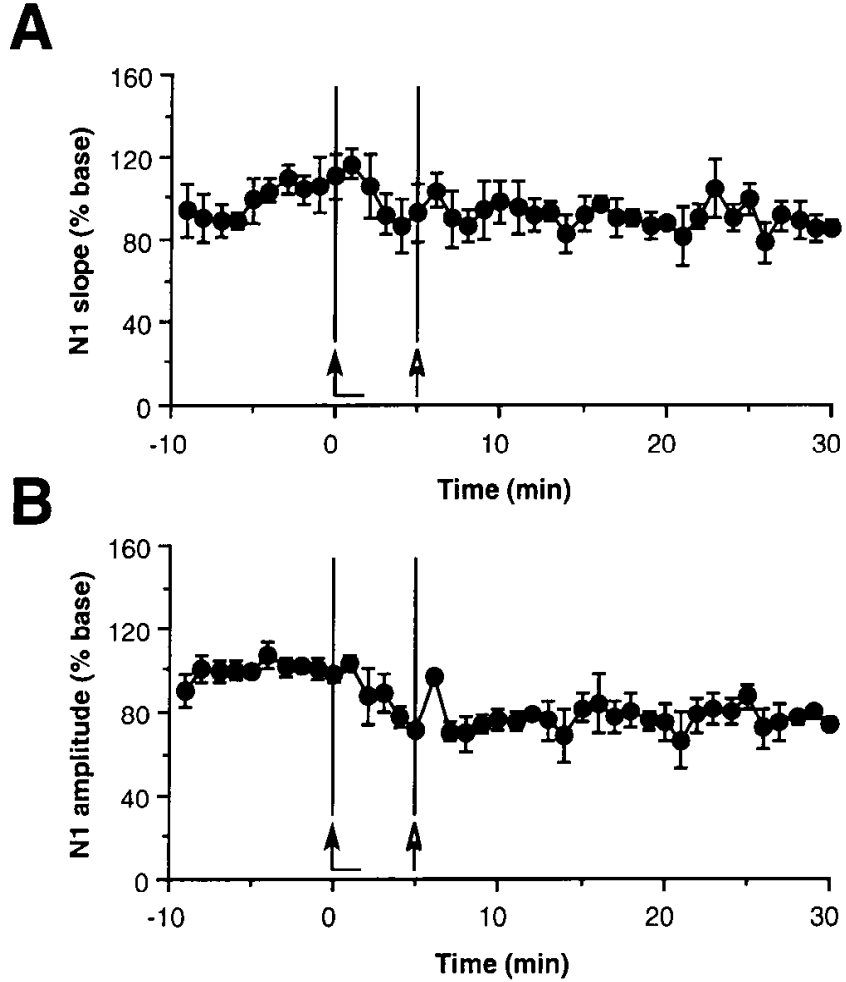

Figure 11. Effect of APV infusion on the induction of BLA LTP. Mean ( \pm SEM) percentage of baseline for $(A) N_{1}$ slope and $(B) N_{1}$ amplitude of BLA field potentials evoked by VAB stimulation in rats receiving APV followed by HFS. The onset and duration of the APV infusion are indicated by the solid arrow and the delivery of HFS by the open arrow. In the presence of APV, HFS did not induce LTP.

Figure 15A; Figure $15 B$ displays the data averaged across the 8 min tests. As shown in Figure 15A, NMDA lesions of the BLA eliminated conditional freezing to both the contextual and acoustic CSs for the duration of the tests. Similarly, ventrocaudal HF lesions attenuated freezing to both contexts and tones, but the magnitude of this attenuation was much greater for the contextual CS (Fig. 15B). This pattern of results was confirmed in an ANOVA with between-subjects factors of group (three levels: $\mathrm{SH}, \mathrm{EC}$, and BL) and within-subjects factors of CS (two levels: context and tone) and test minute (minutes 1-8). The ANOVA revealed significant main effects of group $[F(2,32)=15.1, p$ $<0.0001] . C S[F(1,32)=6.4, p<0.02]$ and test minute $[F(7$, $224)=25.1, p<0.0001]$ and reliable interactions of group and CS $[F(2,32)=4.7, p<0.02]$, group and minute $[F(14,224)$ $=9.6, p<0.0001]$, and $\mathrm{CS}$ and minute $[F(7,224)=4.1, p<$ $0.0001]$. Planned comparisons $(p<0.05)$ indicated that rats with $\mathrm{HF}$ lesions froze to the acoustic $\mathrm{CS}$ reliably more than to the contextual CS. Furthermore, rats with either HF or BLA lesions exhibited similar levels of freezing on the context test, but markedly different levels of freezing on the tone test. Together with the immediate postshock data, these results suggest that ventrocaudal HF lesions produce a selective deficit in fear conditioning to contextual stimuli, whereas BLA lesions produce a general deficit in fear conditioning to both contextual and acoustic CSs. These data confirm the important role for the BLA in fear conditioning and represent the first report of a role for the entorhinal cortex and subiculum in contextual fear conditioning.
A

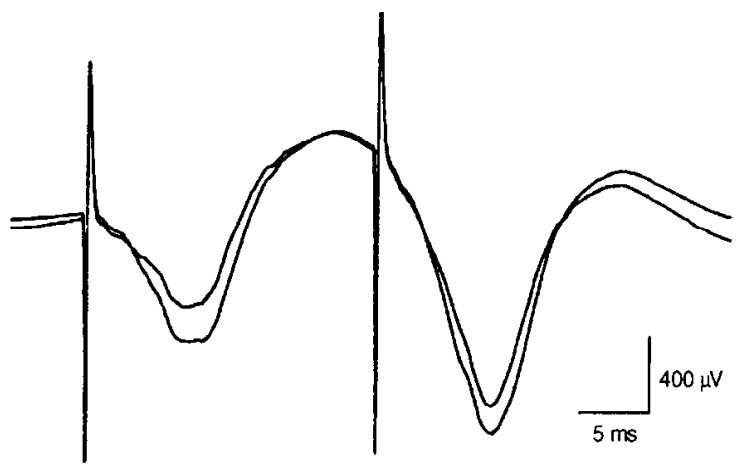

B

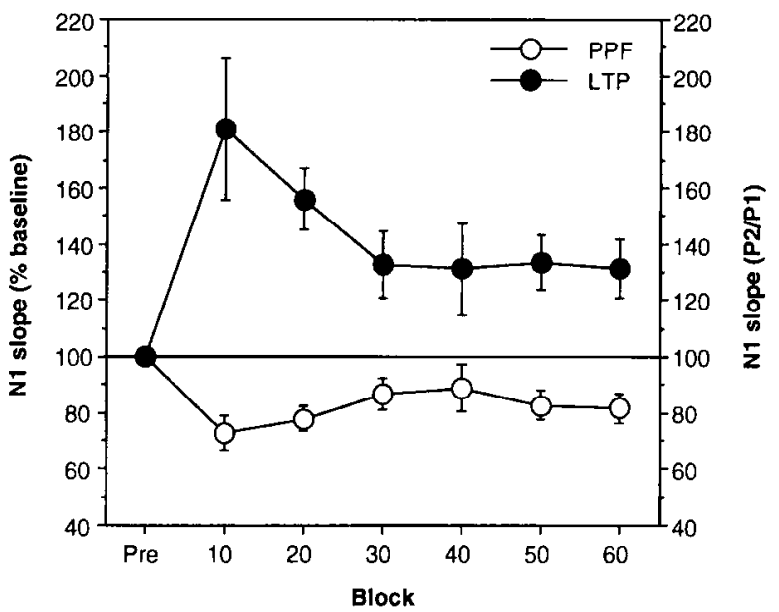

Figure 12. Simultaneous measurement of PPF and LTP of VABevoked responses in the BLA. $A$, Representative BLA field potentials evoked by pairs of pulses ( $20 \mathrm{msec}$ ISI) before and after LTP induction. Waveforms are averages of five evoked responses. Note the relatively greater potentiation of the $N_{1}$ response to the first pulse compared to the second pulse. $B$, Mean ( \pm SEM) $N_{1}$ slope (percent baseline, solid circles) and pulsc ratio (percent baseline, open circles) for the seven 10 min blocks of the recording session. Paired-pulses were used as the test stimuli to permit the simultaneous assessment of both PPF and LTP. High-frequency stimulation (HFS, $10200 \mathrm{msec}$ bursts of $100 \mathrm{~Hz}$ stimulation at $1 \mathrm{~Hz}$ ) was delivered following the $10 \mathrm{~min}$ pre-HFS period (Pre). HFS induced reliable LTP that persisted for the duration of the recording session. The induction of LTP was associated with a correlated decrease in the magnitude of paired pulse facilitation. This decrease in PPF was greatest in the first post-HFS block, which corresponds to a period when presynaptic PTP is maximal.

\section{Discussion}

The present study used extracellular recording techniques to examine synaptic transmission between the HF and the BLA in anesthetized rats. Single-pulse electrical stimulation of the VAB evoked extracellular field potentials in the BLA. The VABevoked field potentials occurred with a short latency, correlated with action potential discharge, and required local neuronal activity mediated by glutamatergic synaptic transmission. Pairedpulses delivered at short ISIs and brief trains of HFS induced short-term changes in synaptic efficacy at HF-BLA synapses. Longer and more numerous trains of HFS induced an enduring, NMDA receptor-dependent LTP of synaptic transmission similar to that observed in other neural circuits. PPF, which is believed to be mediated by presynaptic changes in neurotransmitter release, was markedly reduced following the induction of LTP at 

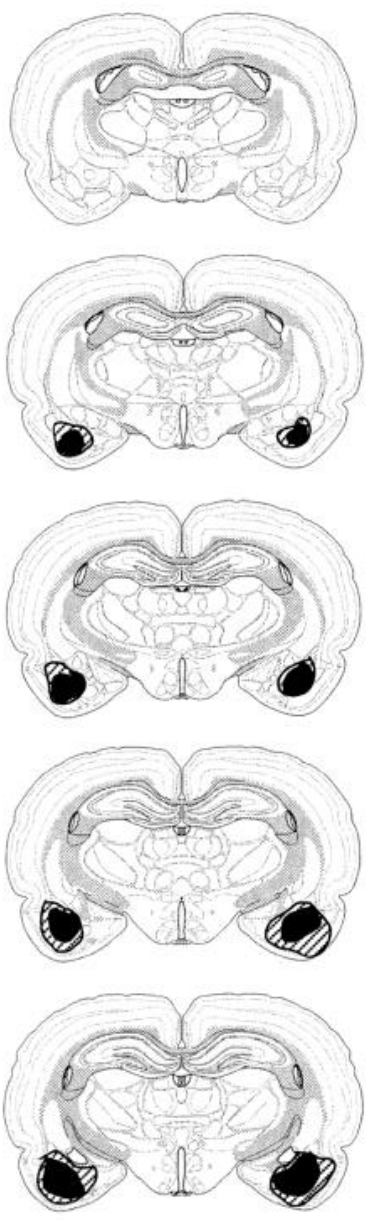

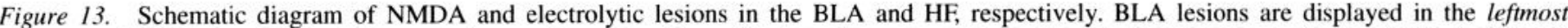

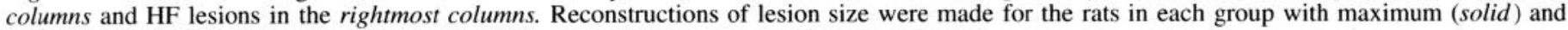
minimum (striped) damage.

HF-BLA synapses. This suggests that LTP at HF-BLA synapses is mediated, at least in part, by an increase in presynaptic glutamate release. The potential importance of HF-BLA projections in learning was indicated by an experiment in which lesions placed in either the ventrocaudal HF or the BLA eliminated the acquisition of fear to contextual cues. Collectively, the results of the present study reveal modifiable neuronal responses in projections from the HF to the BLA. These results are consistent with a role of the HF-BLA pathway in contextual fear conditioning.

\section{Extracellular field potentials as an index of HF-BLA synaptic transmission}

VAB-evoked field potentials in the BLA consisted of a biphasic waveform with fast, negative $\left(N_{1}\right)$ and slow, positive $\left(P_{1}\right)$ components. Several pieces of evidence support the view that these extracellular field potentials are a reliable index of HF-BLA synaptic transmission in vivo. First, we have demonstrated that multiple-unit firing in the amygdala is temporally and spatially correlated with the peak amplitude of $N_{1}$, suggesting that $N_{1}$ reflects, in part, the synchronous discharge of BLA neurons. Second, BLA field potentials are sensitive to manipulations that either increase (paired-pulses, HFS) or decrease (lidocaine, glutamate receptor antagonists) synaptic transmission. The pattern of these results suggests that $N_{1}$ slope is a measure of glutamatergic EPSPs in the BLA. Collectively, these data are consistent with
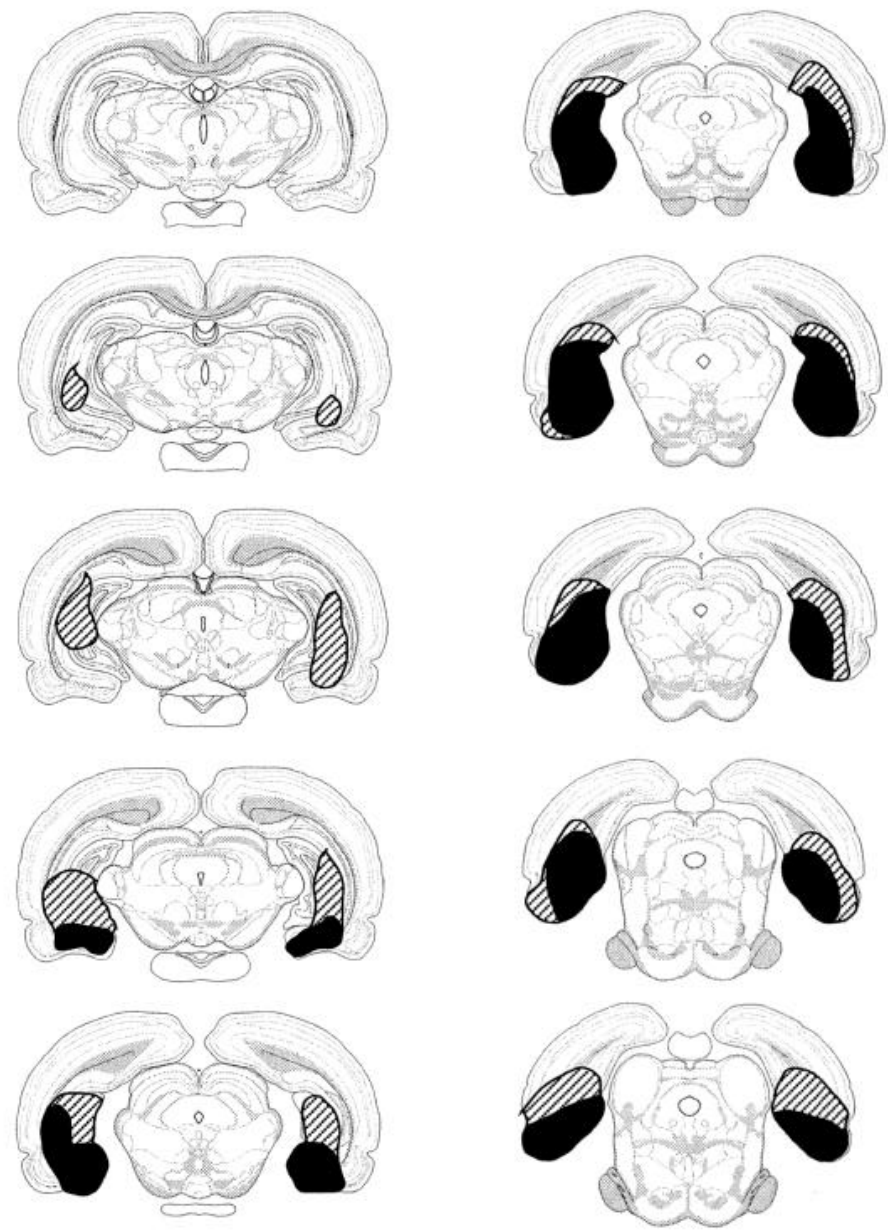

the view that VAB-evoked field potentials are generated by local synaptic conductances and spike firing in the BLA.

Despite this evidence, however, we cannot conclude unequivocally that there are direct correlates of synaptic currents in BLA field potentials without concurrent intracellular and extracellular recordings from BLA neurons. Although such simultaneous recordings have yet to be performed, it may be useful to consider the correlation between our extracellular recordings and the intracellular recordings reported in a series of elegant studies by Finch and colleagues. These investigators recorded intracellular responses in the BLA following HF stimulation in vivo and revealed a consistent pattern of synaptic activation (Mello et al., 1992a). Specifically, HF stimulation generated an initial glutamatergic EPSP followed by a GABAergic IPSP in the majority of BLA neurons. In an extracellular recording in the region of HF-BLA synaptic terminals, this pattern of synaptic activation would be manifest as an initial current sink (from the EPSPs) followed by a current source (from the IPSPs). The latencies and shapes of the negative and positive field potential components we have recorded in the present study are consistent with this profile. Nevertheless, caution must be exercised in extending the results from intracellular recordings in BLA neurons to population field potentials in the BLA. It may be the case, for instance, that the nonlaminar geometry of the BLA severely perturbs the extracellular current sources and sinks generated by local synaptic currents in individual BLA neurons or groups of 


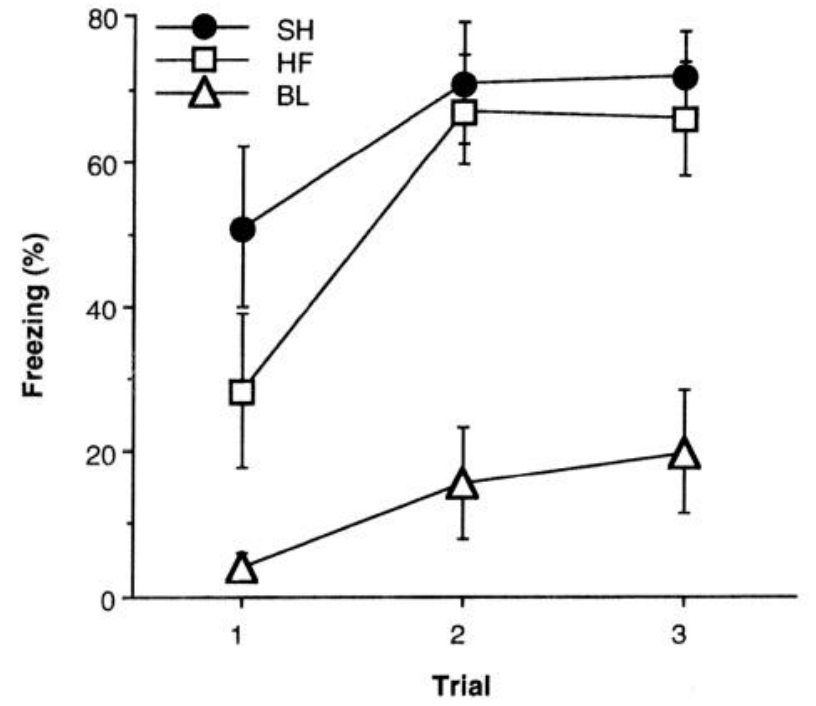

Figure 14. Effects of BLA or ventrocaudal HF lesions on immediate postshock freezing. Mean $( \pm$ SEM $)$ percentage of freezing on the training day following three conditioning trials for rats in each of the three groups [sham $(S H)$, solid circles; ventrocaudal HF lesion $(H F)$, open squares; BLA lesion $(B L)$, open triangles]. Sham rats and rats with ventrocaudal $\mathrm{HF}$ lesions were not different from one another and froze at a high level in the postshock period. In contrast, rats with BLA lesions exhibited severely attenuated levels of freezing that were reliably less than those in both of the other groups.

neurons. Moreover, our paired-pulse experiments suggest that $P_{1}$ is not a population IPSP. Nonetheless, the sensitivity of $N_{1}$ to glutamate antagonists suggests it may be mediated by the glutamatergic EPSPs identified by Mello et al. (1992a).

\section{NMDA and non-NMDA receptor-mediated synaptic transmission in the BLA}

Recent behavioral studies suggest an important role for BLA glutamate receptors in the acquisition and expression of conditioned fear (Miserendino et al., 1990; Jerusalinsky et al., 1992; Fanselow and Kim, 1994). To understand the contribution of glutamate receptors to VAB-evoked field potentials in the BLA, we infused the selective AMPA and NMDA receptor antagonists, DNQX and APV, into the amygdala during recording. In accordance with a previous study of HF-BLA synaptic transmission (Mello et al., 1992b), we found that the slope of the negative component of BLA field potentials and BLA spike firing were severely attenuated by DNQX. This confirms the existence of a prominent AMPA receptor-mediated component in BLA field potentials. We also found that spike firing, but not $N_{1}$ slope, in the BLA was attenuated by APV. Collectively, these results are consistent with a recent report demonstrating that single-unit responses evoked in the lateral amygdala by stimulation of the medial geniculate body are sensitive to both CNQX and APV (Li and LeDoux, 1994). The lack of an effect of APV on $N_{1}$ slope, which we view as a measure of intracellular EPSPs, in our experiments is consistent with the effects of NMDA receptor antagonists in the hippocampus, which involve an attenuation of spike firing, but not EPSPs (Sah et al., 1989; Maren et al., 1992). Thus, there is an NMDA receptor-mediated component to synaptic transmission in the BLA that may be involved in regulating cell excitability (Rainnie et al., 1991; Gean et al., 1993).

While our results suggest that there are both NMDA and AMPA receptor-mediated components to HF-BLA synaptic transmission, there remains the possibility that the high doses of APV (100 mM) and DNQX (10 mm) used in the present study

B

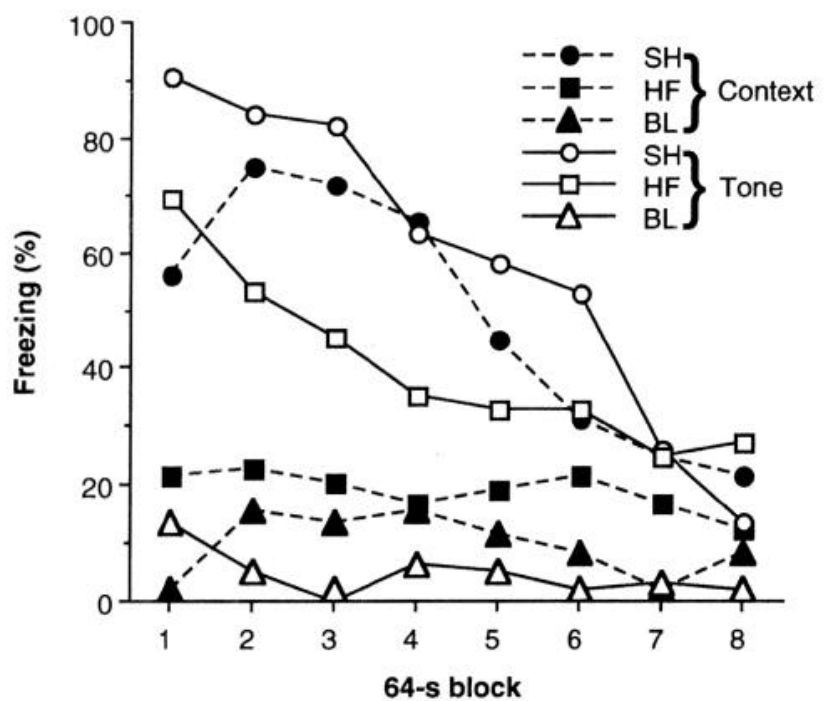

Figure 15. Effects of BLA or ventrocaudal HF lesions on delayed freezing to contextual and acoustic CSs. A, Mean ( \pm SEM) percentage of freezing to the context and tone CSs during each minute (64 sec block) of the test for rats in the three groups [sham ( $\mathrm{SH}$ ), solid circles; BLA lesion $(B L)$, open triangles; ventrocaudal HF lesion $(H F)$, open squares). BLA lesions eliminated conditional freezing to both the context and tone CS, whereas ventrocaudal HF lesions produced a selective attenuation of freezing to the context CS. Groups that exhibited freezing early in the 8 min test showed a graded extinction of freezing across the test. $B$, Mean ( \pm SEM) percentage of freezing to the context and tone CSs collapsed across the $8 \mathrm{~min}$ test for each of the three groups [sham $(\mathrm{SH})$, solid bars; ventrocaudal HF lesion $(H F)$, hatched bars; BLA lesion $(B L)$, open bars]. This representation of the data emphasizes the reliable interaction between group and conditional stimulus. 
produced nonselective effects on synaptic function. Indeed, Chapman and Bellevance (1992) have reported the paradoxical result that high doses of APV $(100 \mu \mathrm{M})$ in vitro attenuate synaptic transmission in amygdaloid circuits that apparently lack NMDA receptors. Nonetheless, our results are consistent with those of Li and LeDoux (1994), who used much lower doses of CNQX and APV to reveal AMPA and NMDA receptor-mediated components to thalamo-amygdala synaptic transmission in vivo. Our findings are also consistent with in vitro studies demonstrating the existence of both AMPA and NMDA receptormediated conductances in neurons of the BLA (Rainnie et al., 1991).

With regard to behavioral studies, the discovery of NMDA receptor-dependent LTP at HF-BLA synapses suggests that the deleterious effects of APV on contextual fear conditioning (Fanselow and Kim, 1994) are mediated through a blockade of BLA LTP. Furthermore, the marked effect of APV on cell excitability in the amygdala, particularly at the doses used in behavioral studies, suggests that it might block not only the acquisition, but also the performance of learning tasks that require the amygdala.

\section{Sinaptic plasticity at in the BLA}

In our characterization of HF-BLA synaptic transmission we identified both short- and long-term forms of synaptic plasticity. A prototypical example of short-term synaptic plasticity that we observed is PPF, for which the $N$, response to the second pulse of a closely-spaced pair of pulses was augmented relative to the response evoked by the lirst pulse. The facilitation we observed was quite similar to that in other neural circuits, exhibiting a dependence on both ISI and stimulus intensity. In general, the facilitation was most robust at short ISIs (10-20 msec) and submaximal $(400-800 \mu \mathrm{A})$ stimulation intensities. Although we did not quantify the time-constant for decay of PPF, the facilitation was clearly short-lived as it decayed within the $10 \mathrm{sec}$ interval between tests.

In addition to short-term synaptic plasticity, we found that repeatedly applying high-frequency trains of stimulation to the VAB induced a persistent increase in BLA synaptic transmission. As in the hippocampus, the induction of BLA LTP required NMDA receptor activation. NMDA receptor-dependent LTP in the amygdala has also been reported in vitro (Gean et al., 1993; but see Chapman and Bellevance, 1992). And although several additional experiments are required to further characterize the expression of BLA LTP, we have made some progress in identifying a potential mechanism. Using paired-pulses as a probe for presynaptic functionality, we found that ITP induction was associated with a marked reduction in PPF. The occlusion of PPF by LTP induction suggests that some component of BLA LTP is mediated by an increase in the probability of presynaptic neurotransmitter release (e.g., Zalutsky and Nicoll, 1990). However, it remains possible that the reduction in PPF is due to an increase in the number of high-probability release sites (Schulz. et al., 1994), a change that could be mediated by the addition of postsynaptic AMPA receptors (Maren et al., 1993) to previously AMPA receptor-free synapses (Liao et al., 1995).

\section{Behavioral significance of $H F-B L A \quad L T P$}

As a first step in understanding the contribution HF-BLA synaptic plasticity to learning and memory, we examined the impact of destroying IIF and BLA ncurons on the acquisition of Pavlovian fear conditioning to contextual and discrete stimuli. Electrolytic lesions of the ventrocaudal HF (entorhinal cortex, ventral subiculum, and $V A B$ ) produced a selective deficit in the acquisition of fear to a contextual CS, whereas NMDA lesions of the BLA produced a nonselective deficit in the acquisition of fear to both contextual and acoustic CSs. Interestingly, ventrocaudal HF lesions, unlike BLA lesions, did not impact the context free - $^{-}$ ing that occurs immediately following footshock during conditioning. This suggests that there is a short-lived context memory spared by ventrocaudal HF lesions. Overall, this pattern of results is consistent with the hypothesis that the BLA is a critical site for the convergence of CS and US information during conditioning (e.g., Romanski et al., 1993). They further suggest that the HF is a component of a modifiable CS pathway that conveys information concerning the context to the BLA. Of course, one could argue that attenuated context conditioning in rats with ventrocaudal HF lesions is not due to a loss of efferents to the amygdala, but to a loss of efferents to the dorsal hippocampus. which has also been shown to be important for context conditioning (Kim and Fanselow, 1992; Phillips and LeDoux. 1992). Direct projections from the hippocampus (area $\mathrm{CA}_{1}$ ) to the BLA. then, could be the critical context pathway to the BLA. We are currently performing experiments to test this hypothesis.

The virtual elimination of fear conditioning by NMDA lesions of the BLA is not surprising in light of numerous studies implicating the BLA in aversive learning (e.g., Cahill and McGaugh, 1990; LeDoux et al., 1990; Maren et al., 1991; Helmstetter, 1992; Sananes and Davis, 1992). However, it is not clear from the present study whether the severe attenuation of conditional freezing in rats with BLA lesions is due to a leaning or performance deficit. Indeed, there is reason to believe that the amygdala, particularly the central nucleus, has an important role in the performance of conditional fear responses, including freezing. Nonetheless, a large body of data maintains the critically important role of the BLA in the acquisition of conditional fear and it is in this capacity, we believe, that the BLA requires synaptic plasticity for its memorial function.

\section{Conclusions}

In the present study, electrophysiological procedures were used to identify and characterize synaptic responses and synaptic plasticity in the BLA following HF stimulation in viro. Extracellular field potentials evoked in the BLA exhibited both shortand long-term forms of synaptic plasticity, including PPF and NMDA receptor-dependent LTP. A role for these processes in learning and memory was suggested by behavioral experiments that demonstrated a critical role for the HF and the BLA in the acquisition of conditional fear to contextual stimuli. Future experiments will examine HF-BLA synaptic transmission in awake, behaving rats to provide a more rigorous examination of the role of BLA LTP in Pavlovian fear conditioning. It is hoped that knowledge gained from these studies will further our understanding of the synaptic mechanisms of learning and memory, generally.

\section{References}

Bliss TVP, Gardner-Medwin AR (1973) Long-lasting potentiation of synaptic transmission in the dentate area of the unanesthetized rabbit following stimulation of the perforant path. J Physiol (Lond) 2.32: 357-374.

Bliss TVP, Lømo T (1973) Long-lasting potentiation of synaptic transmission in the dentate area of the anesthetized rabbit following stimulation of the perforant path. J Physiol (Lond) 232:331-356.

Cahill L, McGaugh JL (1990) Amygdaloid complex lesions differentially affect retention of tasks using appetitive and aversive reinforcement. Behav Neurosci 104:532-543. 
Canteras NS, Swanson LW (1992) Projections of the ventral subiculum to the amygdala, septum, and hypothalamus: a PHAL anterograde tract-tracing study in the rat. J Comp Neurol 324:180-194.

Chapman PF, Bellevance LL (1992) Induction of long-leim potentiation in the basolateral amygdala does not depend on NMDA receptor activation. Synapse 11:310-318

Chapman PF, Kairiss EW, Keenan CL, Brown 'TH (1990) Long-term synaptic potentiation in the amygdala. Synapse 6:271-278.

Clugnet MC, LeDoux JE (1990) Synaptic plasticity in fear conditioning circuits: induction of LTP in the lateral nucleus of the amygdala by stimulation of the medial geniculate body. J Neurosci 10:2818-2824.

Collingridge GI , Kehl S.I, Mcl ennan H (1983) Excitatory amino acids in synaptic transmission in the Schaffer collateral-commissural pathway of the rat hippocampus. J Physiol (Lond) 334:33-46.

Davis M, Rainnie D, Cassell M (1994) Neurotransmission in the rat amygdala related to fear and anxiety. Trends Neurosci 17:208-214.

Fanselow MS, Kim JJ (1994) Acquisition of contextual Pavlovian fear conditioning is blocked by application of an NMDA receptor antagonist D,L-2-amino-5-phosphonovaleric acid to the basolateral amygdala. Behav Neurosci 108:210-212.

Gean PW, Chang FC, Huang CC, Lin JH, Way LJ (1993) Long-term enhancement of EPSP and NMDA receptor-mediated synaptic transmission in the amygdala. Brain Res Bull 31:7-11.

Helmstetter FJ (1992) The amygdala is essential for the expression of conditional hypoalgesia. Behav Neurosci 106:518-528.

Izquierdo I, Bianchin M, Silva MB, Zanatta MS, Walz R, Ruschel AC, da Silva RC, Paczko N, Medina JH (1993) CNQX infused into rat hippocampus or amygdala disrupts the expression of memory of two different tasks. Behav Neural Biol 59:1 4.

Jerusalinsky D, Ferreira MBC, Walz R, da Silva RC, Bianchin M, Ruschel AC, Zanatta MS, Medina JH, Izquierdo I (1992) Amnesia by post-training infusion of glutamate receptor antagonists into the amygdala, hippocampus, and entorhinal cortex. Behav Neural Biol 58:76-80.

Kim JJ, Fanselow MS (1992) Modality-specific retrograde amnesia of fear. Science 256:675-677.

Kim M, Campeau S, Falls WA, Davis M (1993) Infusion of the nonNMDA receptor antagonist $C N Q X$ into the amygdala blocks the expression of fear-potentiated startle. Behav Neural Biol 59:5-8.

LeDoux JE, Cicchetti P, Xagoraris A, Romanski LM (1990) The lateral anygdaloid nucleus: sensory interface of the amygdala in fear conditioning. J Neurosci 10:1062-1069.

Li XF, LeDoux JE (1994) Synaptic transmission in the auditory thalamo-amygdala pathway requires joint activation of AMPA and NMDA receptors. Soc Neurosci Abstr 20:274.

Liang KC, Hon W, Davis M (1994) Pre- and posttraining infusion of $N$-methyl-D-aspartate receptor antagonists into the amygdala impair memory in an inhibitory avoidance task. Behav Neurosci 108:241253.

Liao D, Hessler NA, Malinow R (1995) Activation of postsynaptically silent synapses during pairing-induced LTP in CAl region of hippocampal slice. Nature 375:400-404.

Maren S, Baudry M (1995) Properties and mechanisms of long-term synaptic plasticity in the mammalian brain: relationships to learning and memory. Neurobiol Learn Memory 63:1-18

Maren S, Poremba A, Gabriel M (1991) Basolateral amygdaloid multiunit neuronal correlates of discriminative avoidance conditioning in rabbits. Brain Res 549:311-316.
Maren S, Baudry M, Thompson RF (1992) Effects of the novel NMDA receptor antagonist, CGP 39551, on field potentials and the induction and expression of LTP in the dentate gyrus in vivo. Synapse 11:221228.

Maren S, Tocco G, Standley S, Baudry M, Thompson RF (1993) Postsynaptic factors in the expression of long-term potentiation (LTP): increased glutamate receptor binding following LTP induction in vivo. Proc Natl Acad Sci (USA) 90:9654-9658.

Mello LEAM, Tan AM, Finch DM (1992a) Convergence of projections from the rat hippocampal formation, medial geniculate and basal forebrain onto single amygdaloid neurons: an in vivo extra- and intracellular electrophysiological study. Brain Res 587:24-40.

Mello LEAM, Tan AM, Finch DM (1992b) GABAergic synaptic transmission in projections from the basal forebrain and hippocampal formation to the amygdala: an in vivo iontophoretic study. Brain Res $587: 41-48$.

Miserendino MJD, Sananes CB, Melia KR, Davis M (1990) Blocking of acquisition but not expression of fear-potentiated startle by NMDA antagonists in the amygdala. Nature 345:716-718.

Morris RGM, Anderson E, Lynch GS, Baudry M (1986) Selective impairment of learning and blockade of long-term potentiation by an $N$-methyl-D-aspartate antagonist. Nature 319:774-776.

Muller D, Joly M, Lynch $G$ (1988) Contributions of quisqualate and NMDA receptors to the induction and expression of LTP. Science 242:1694-1697.

Ottersen OP (1982) Connections of the amygdala of the rat. IV. Corticoamygdaloid and intraamygdaloid connections as studies with axonal transport of horseradish peroxidase. J Comp Neurol 205:30-48.

Phillips RG, LeDoux JE (1992) Differential contribution of amygdala and hippocampus to cued and contextual fear conditioning. Behav Neurosci 106:274-285.

Racine RJ, Milgram NW, Hafner S (1983) Long-term potentiation phenomena in the rat limbic forebrain. Brain Res 260:217-231.

Rainnie DG, Asprondini EK, Shinnick-Gallagher P (1991) Excitatory transmission in the basolateral amygdala. J Neurophysiol 66:986998.

Romanski LM, Clugnet MC, Bordi F, LeDoux JE (1993) Somatosensory and auditory convergence in the lateral nucleus of the amygdala. Behav Neurosci 107:444-450.

Sah P. Hestrin S, Nicoll RA (1989) Tonic activation of NMDA receptors by ambient glutamate enhances excitability of neurons. Science 246:815-818.

Sananes CB, Davis M (1992) N-Methyl-D-aspartate lesions of the lateral and basolateral nuclei of the amygdala block fear-potentiated startle and shock sensitization. Behav Neurosci 99:342-380.

Schulz PE, Cook EP, Johnston D (1994) Changes in paired-pulse facilitation suggest presynaptic involvement in long-term potentiation. J Neurosci 14:5325-5337.

Shahi K, Baudry M (1992) Increasing binding affinity of agonists to glutamate receptors increases synaptic responses at glutamatergic synapses. Proc Natl Acad Sci USA 89:6881-6885.

Xiao P, Staubli U, Kessler M, Lynch G (1991) Selective effects of aniracetam across receptor types and forms of synaptic facilitation in hippocampus. Hippocampus 1:373-380.

Zalutsky RA, Nicoll RA (1990) Comparison of two forms of long-term potentiation in single hippocampal neurons. Science 248:1619-1624. Zucker RS (1989) Short-term synaptic plasticity. Annu Rev Neurosci 12:13-31. 